\title{
A developmentally regulated translational control pathway establishes the meiotic chromosome segregation pattern
}

\author{
Luke E. Berchowitz, ${ }^{1,2}$ Aaron S. Gajadhar, ${ }^{1}$ Folkert J. van Werven, ${ }^{1,2}$ Alexandra A. De Rosa, ${ }^{1,2}$ \\ Mariya L. Samoylova, ${ }^{1,2}$ Gloria A. Brar, ${ }^{2,3,4}$ Yifeng Xu, ${ }^{5}$ Che Xiao, ${ }^{5}$ Bruce Futcher, $^{5}$ \\ Jonathan S. Weissman, ${ }^{2,3,4}$ Forest M. White, ${ }^{1}$ and Angelika Amon ${ }^{1,2,6}$ \\ ${ }^{1}$ Koch Institute for Integrative Cancer Biology, Massachusetts Institute of Technology, Cambridge, Massachusetts 02139, USA; \\ ${ }^{2}$ Howard Hughes Medical Institute, ${ }^{3}$ Department of Cellular and Molecular Pharmacology, University of California at San \\ Francisco, San Francisco, California 94158, USA; ${ }^{4}$ California Institute for Quantitative Biosciences, San Francisco, California \\ 94158, USA; ${ }^{5}$ Department of Molecular Genetics and Microbiology, Stony Brook University, Stony Brook, New York 11794, USA
}

Production of haploid gametes from diploid progenitor cells is mediated by a specialized cell division, meiosis, where two divisions, meiosis I and II, follow a single S phase. Errors in progression from meiosis I to meiosis II lead to aneuploid and polyploid gametes, but the regulatory mechanisms controlling this transition are poorly understood. Here, we demonstrate that the conserved kinase Ime 2 regulates the timing and order of the meiotic divisions by controlling translation. Ime2 coordinates translational activation of a cluster of genes at the meiosis I-meiosis II transition, including the critical determinant of the meiotic chromosome segregation pattern $C L B 3$. We further show that Ime2 mediates translational control through the meiosis-specific RNA-binding protein Rim4. Rim4 inhibits translation of CLB3 during meiosis I by interacting with the 5' untranslated region (UTR) of CLB3. At the onset of meiosis II, Ime2 kinase activity rises and triggers a decrease in Rim4 protein levels, thereby alleviating translational repression. Our results elucidate a novel developmentally regulated translational control pathway that establishes the meiotic chromosome segregation pattern.

[Keywords: meiosis; RNA-binding protein; translational control; cyclins; gametogenesis; kinase; untranslated region] Supplemental material is available for this article.

Received June 12, 2013; revised version accepted September 3, 2013.

Species that reproduce sexually depend on the production of the haploid products of meiosis, called gametes, for passing the genetic material to successive generations. These cells are subsequently used in fertilization, resulting in the restoration of the progenitor's chromosomal complement. In meiosis, cells segregate their chromosomes twice sequentially without an intervening DNA synthesis phase. The first meiotic division is unusual in that homologous chromosomes are segregated. Meiosis II resembles mitosis in that sister chromatids are partitioned.

Translational control plays a critical role in bringing about the modifications to the cell cycle necessary to transform mitosis into meiosis (Nakamura and Seydoux 2008; Kronja and Orr-Weaver 2011). This is best exemplified by the fact that in most organisms in which germ cell development is well characterized, mRNA transcription is shut down during gametogenesis. The point during

${ }^{6}$ Corresponding author

E-mail angelika@mit.edu

Article is online at http://www.genesdev.org/cgi/doi/10.1101/gad.224253.113. germ cell development when this occurs varies among species, but from this point forward, cells must rely on the translational activation and repression of previously transcribed mRNAs to regulate gene expression. A handful of well-characterized examples have demonstrated the mechanistic diversity of message-specific translational control. The majority of germline-specific translational control is achieved via tightly regulated feedback-sensitive combinations of mRNA-protein and protein-protein interactions. These regulatory networks modulate poly-A tail length, 3' untranslated region (UTR) length, and mRNA closed loop formation, all of which are thought to affect translation initiation-requiring interactions at the 5' cap. Despite the importance of translational control, mechanistic insight into cis- and trans-acting factors

(C) 2013 Berchowitz et al. This article is distributed exclusively by Cold Spring Harbor Laboratory Press for the first six months after the fullissue publication date (see http://genesdev.cshlp.org/site/misc/terms. xhtml). After six months, it is available under a Creative Commons License (Attribution-NonCommercial 3.0 Unported), as described at http://creativecommons.org/licenses/by-nc/3.0/. 
governing message-specific translational control has been difficult to attain. We have a detailed understanding of very few translational control regulatory modules, especially when compared with analogous knowledge of transcriptional control.

Post-transcriptional mRNA regulation is required for germ cell specification and maturation in many, and perhaps all, eukaryotes (for review, see Thompson et al. 2007). RNA-binding proteins that affect both the translational repression (such as nanos family proteins) (Asaoka-Taguchi et al. 1999) and activation (such as vasa family proteins) (Gavis et al. 1996) of mRNAs are critical in germline development. In Xenopus and Drosophila, phosphorylation-mediated translational control of cyclins, the regulatory subunits of cyclin-dependent kinases (CDKs), is required for proper progression through the gametogenesis program (Radford et al. 2008; Vardy et al. 2009). In budding yeast, too, proper regulation of the B-type cyclin Clb3 is critical for gametogenesis, known as sporulation in yeast. Presence of Clb3 prior to the meiotic divisions results in the suppression of meiosis I. Instead, cells undergo a mitosis-like division, segregating sister chromatids rather than homologs (Carlile and Amon 2008; Miller et al. 2012).

The regulatory mechanisms acting on CLB3 are complex. Clb3 expression is regulated at both the transcriptional and translational level (Carlile and Amon 2008). CLB3 mRNA is produced as a target of the transcription factor Ndt80 at the onset of meiosis I, but Clb3 protein is restricted to meiosis II through translational repression during meiosis I. This stands in contrast to the other meiotically expressed B-type cyclins, which are efficiently translated throughout meiosis. Translational control of CLB3 depends on its 153-base-pair (bp) 5' UTR. This region of the transcript is both necessary and sufficient to restrict translation to meiosis II, but the mechanism whereby it mediates this regulation is not understood.

Here, we elucidate a translational control pathway that coordinates the expression of a group of critical mRNAs that, like $C L B 3$, is only translated during meiosis II. Importantly, we also define the regulatory mechanisms restricting translation of this group of transcripts to the second meiotic division. The meiosis-specific RNA-binding protein Rim4 binds to the 5' UTR of CLB3 and inhibits its translation during meiosis I. Rim4 translational inhibitory activity is restricted to meiosis I by the sporulation-specific protein kinase Ime2. At the onset of meiosis II, the activity of the protein kinase dramatically increases and triggers the decline in Rim4 protein, thereby alleviating translational repression. Our results demonstrate that a developmentally regulated translational control pathway is a central determinant of the meiotic chromosome segregation pattern.

\section{Results}

\section{Ime2 regulates translational control in meiosis}

Translational repression of CLB3 during meiosis I is readily observed in cultures induced to progress through meiosis by release from a prophase I block (Benjamin et al.
2003; Carlile and Amon 2008). In this synchronization procedure, cells are reversibly arrested in meiotic prophase I by restricting the expression of the gene encoding the transcription factor Ndt80. Cells carrying NDT80 under control of the GAL1-10 promoter and a Gal4estrogen receptor fusion (GAL4.ER) will arrest in prophase $I$ in the absence of estrogen. Upon addition of $\beta$-estradiol, the cells rapidly activate NDT80 and undergo the meiotic divisions in a highly synchronous manner. CLB3 mRNA rapidly accumulates upon release from the prophase I block, but Clb3 protein does not accumulate until meiosis II (Fig. 1A; Carlile and Amon 2008).

To elucidate the mechanism of translational control operating on $C L B 3$, we investigated a potential role of two key regulators of the meiotic cell cycle in this process: Clb-CDKs and the meiosis-specific protein kinase Ime2. We hypothesized that if either kinase was critical for translational control of $C L B 3$, its misregulation, particularly during meiosis I, may interfere with translational control of CLB3. Overexpression of the major meiosis I B-type cyclin CLB1 from the copperinducible CUP1 promoter did not interfere with CLB3 translational control (Supplemental Fig. S1). In contrast, increasing Ime2 kinase activity interfered with CLB3 translation inhibition (Fig. 1A,B).

IME2 encodes a highly conserved serine-threonine kinase that is required for entry into sporulation (Smith and Mitchell 1989; Kominami et al. 1993; SzwarcwortCohen et al. 2009). Ime2 is essential for the initiation of premeiotic $S$ phase because it targets the S-phase CDK inhibitor Sic1 for degradation (Dirick et al. 1998). IME2 is also highly expressed during the meiotic divisions, the significance of which is unknown (Benjamin et al. 2003). To increase Ime2 kinase activity during meiosis I, we employed a stabilized allele that lacks the C-terminal 241 amino acids (henceforth IME2st) (Sia and Mitchell 1995; Sari et al. 2008). Expression of IME2st led to higher levels of Ime2 protein during meiosis I (Supplemental Fig. S2) and kinase activity (see below).

The IME2st allele affects the kinetics of meiosis. Cells expressing IME2st exhibit a decreased ability to enter the meiotic divisions and display a delay in progression through meiosis I (Fig. 1A). The IME2st allele also had a striking effect on CLB3 translation. Whereas Clb3 protein levels were restricted to meiosis II in wild-type cells, IME2st cells produced Clb3 protein as soon as the RNA was expressed during entry into meiosis I (Fig. 1A). The dramatic effect of the IME2st allele on CLB3 translation was most evident in cells in which the GAL1-10 promoter was placed 153 bp upstream of CLB3 ( $p G A L-5^{\prime}$ $\left.U T R_{C L B 3} C L B 3\right)$, thus placing $C L B 3$ expression under control of the GAL1-10 promoter while leaving the $C L B 3$ 5' UTR, which confers translational control, intact. $p G A L-5^{\prime} U T R_{C L B 3} C L B 3$ cells exhibit high levels of $C L B 3$ mRNA during meiosis I after induction with $\beta$-estradiol, but translation is nevertheless restricted to meiosis II (Fig. 1B; Carlile and Amon 2008). In contrast, CLB3 expressed from the $p G A L-5^{\prime} U T R_{C L B 3} C L B 3$ construct was aberrantly translated in IME2st cells during meiosis I (Fig. 1B). The loss of CLB3 translational control is not 


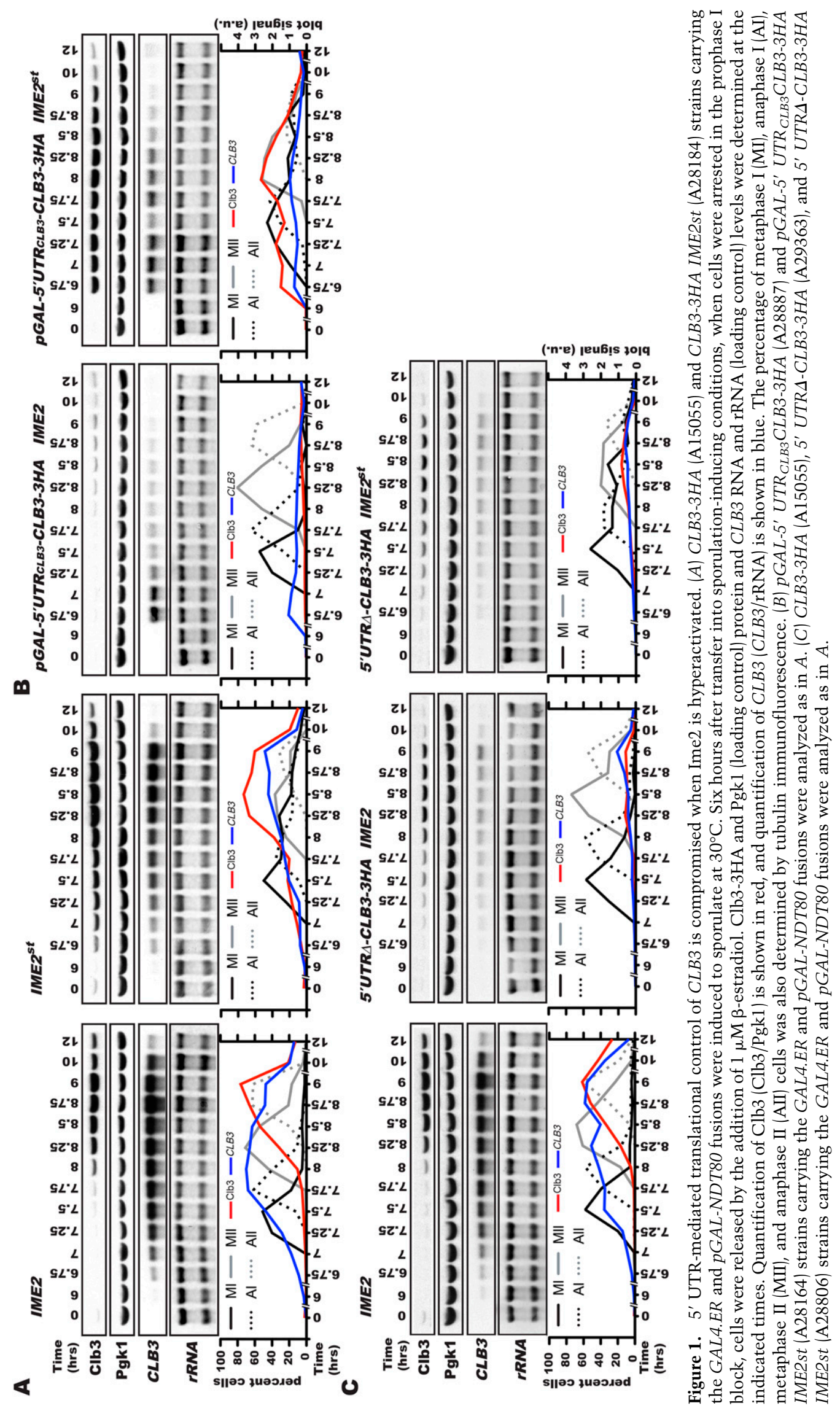


simply a consequence of slowed meiotic progression in IME2st-expressing cells because expression of the hyperstable IME2st allele delays cells in meiosis I, when CLB3 is normally not translated (Fig. 1A,B). We conclude that when Ime2 is hyperactive, meiosis I CLB3 translational repression is lost.

To determine whether the IME2st allele exerts its effect on CLB3 translation through the 5' UTR of CLB3, we analyzed CLB3 mRNA and protein production in strains in which the $5^{\prime}$ UTR of CLB3 was deleted $15^{\prime}$ UTR 4 -CLB3). Transcription of CLB3 is decreased when the $5^{\prime}$ UTR is deleted, but the small amounts of RNA that are made are translated even during meiosis I (Fig. 1C), consistent with CLB3 translational control being mediated by its 5' UTR. Translational efficiency of CLB3 was not increased in $5^{\prime} U T R \Delta-C L B 3$ cells expressing the IME2st allele, indicating that IME2 acts through the $5^{\prime}$ UTR of $C L B 3$ to modulate $C L B 3$ translational efficiency.

Ime2 regulates the message-specific translation of a cluster of genes, including CLB3

mRNA deep sequencing and ribosomal profiling of synchronized meiotic cultures identified eight other genes-YSP2, SPO20, GIP1, STV1, SPS1, ECM8, YFL012W, and HXT14whose pattern of translation is very similar to CLB3 (Brar et al. 2012). Our analysis of SPO20, GIP1, and SPS1 confirmed this result. Whereas transcripts were present in meiosis I and meiosis II, proteins were present only during meiosis II (Fig. 2A-C). We conclude that CLB3 is part of a group of genes whose translation is restricted to meiosis II. We refer to this group of genes as the IME2regulated gene cluster.

To assess the extent to which IME2 regulates translation in meiosis, we examined whether modulating Ime2 levels also affects translation of other members of the IME2-regulated gene cluster. Indeed, SPO20, GIP1, and SPS1 translational repression was alleviated upon expression of the IME2st allele (Fig. 2A-C). Conversely, inactivation of IME2 using an allele of IME2 that can be selectively inhibited by addition of 4-amino-1-tert-butyl3-(1'-naphthyl)pyrazolo[3,4-d]pyrimidine (1-NA-PP1, Toronto Research Chemicals) to the culture at later stages of meiosis (ime2-as1) (Benjamin et al. 2003) prevented translation of GIP1 during meiosis II (Supplemental Fig. S3). We note that while the 5' UTRs of genes within the $C L B 3$ gene cluster are highly conserved among yeasts of the Saccharomyces genus (Supplemental Fig. S4), we did not detect shared motifs or secondary structures among them (data not shown).

To assess whether expression of IME2st leads to a global increase in translational efficiency rather than a messagespecific one, we investigated the effect of IME2st on translation of the meiosis-specific gene SPO21. This gene is expressed specifically during the meiotic divisions, but mRNA sequencing (mRNA-seq) and ribosomal profiling did not place it in the IME2-regulated gene cluster (Brar et al. 2012). Stabilization of Ime2 did not result in increased translation of SPO21 (Fig. 2D). This observation combined with the fact that our loading controls Pgk1 and Kar2 were unresponsive to IME2st expression argues that Ime 2 acts in a message-specific manner rather than as a global translational enhancer. We noted that expression of IME2st led to changes in Spo21 mobility. SPO21 mRNA also accumulated prior to Spo21 protein, raising the possibility that SPO21 exhibits Ime2-independent translational control. We conclude that IME2 governs the translation of a group of genes whose function is needed during meiosis II and spore formation.

\section{IME2st expression is sufficient to alleviate translational repression in prophase $I$}

To determine how IME2 regulates translation of meiosis II-specific genes, we focused our studies on CLB3. First, we showed that $C L B 3$ is translated as early as prophase I, prior to the meiotic divisions in IME2st cells. We arrested cells in prophase I by deleting NDT80 and then forced expression of CLB3 with its native 5' UTR (pGAL-5' $\left.U T R_{C L B 3} C L B 3\right)$. Upon induction of the GAL1-10 promoter by $\beta$-estradiol addition in wild-type cells, CLB3 mRNA was produced at high levels, but little if any Clb3 protein accumulated (Fig. 3A). In contrast, high levels of Clb3 protein accumulated as soon as the mRNA was expressed in IME2st cells (Fig. 3B). As observed previously (Miller et al. 2012), soon after Clb3 protein began to accumulate, cells started to form bipolar spindles. Our findings indicate that the machinery that represses translation during meiosis I is already active during prophase I. Our data further show that expression of the IME2st protein is sufficient to down-regulate this regulatory mechanism, indicating that translational competency is acutely responsive to Ime 2 activity.

The above experiments were conducted under experimental conditions that involved a prolonged arrest in prophase I, such as is seen in cells in which the recombination checkpoint is activated (Hepworth et al. 1998). It was thus possible that CLB3 translational control is a result of this prolonged arrest. To test this possibility, we developed an alternate method to generate synchronous meiotic cultures. Translational inhibition of CLB3 during meiosis $\mathrm{I}$ is not seen in synchronous sporulation experiments using traditional nutrient starvation methods (Grandin and Reed 1993) due to inadequate resolution of the meiotic divisions. To obtain a higher degree of synchrony in sporulation experiments involving synchronization by starvation, we placed two factors critical for entry into gametogenesis, IME1 and $I M E 4$, under the control of the CUP1 promoter. Upon transfer of cells into sporulation-inducing conditions, we induced expression of the two factors by adding $\mathrm{CuSO}_{4}$. $\mathrm{CuSO}_{4}$ addition caused cells to undergo premeiotic DNA replication and the meiotic divisions with unprecedented synchrony (Fig. 4A-C). As in the prophase I block-release system, we observed that Clb3 translation was restricted to meiosis II (Fig. 4D). Thus, Clb3 translational control is not a consequence of manipulating NDT80 expression. Notably, using this synchronization system, we found that, as previously reported for Ime2 kinase activity (Benjamin et al. 2003), Ime2 protein levels peak during premeiotic $S$ phase and during the meiotic divisions 
A

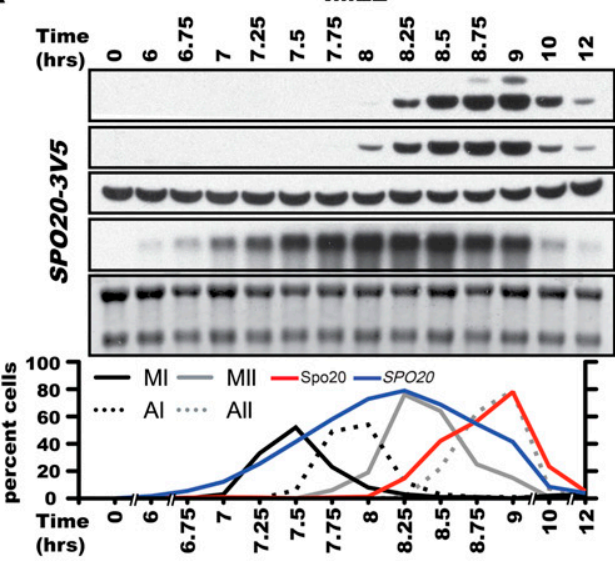

B

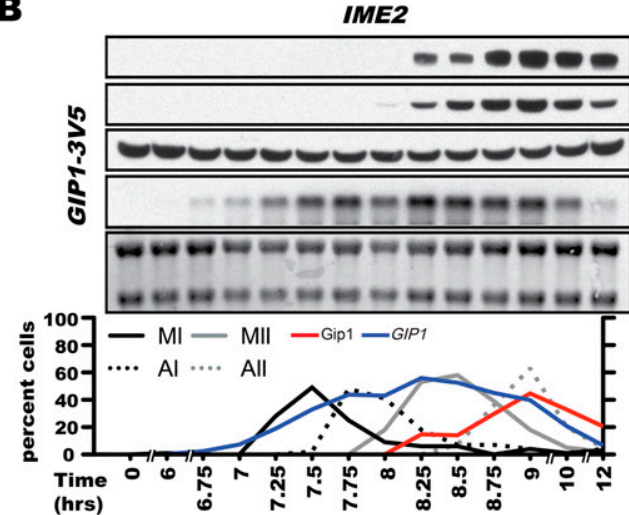

C

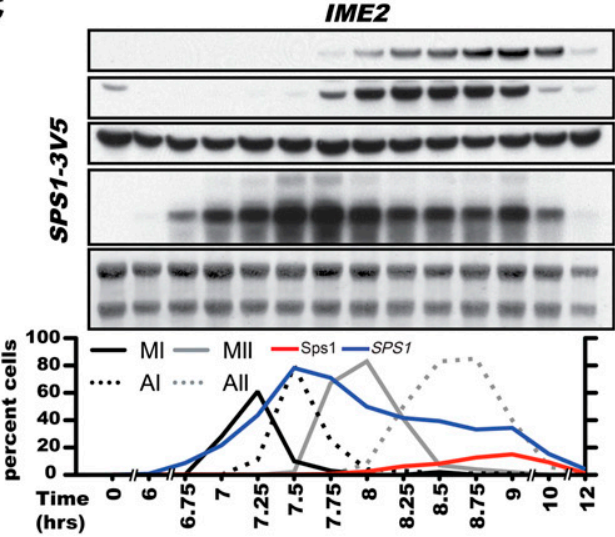

D
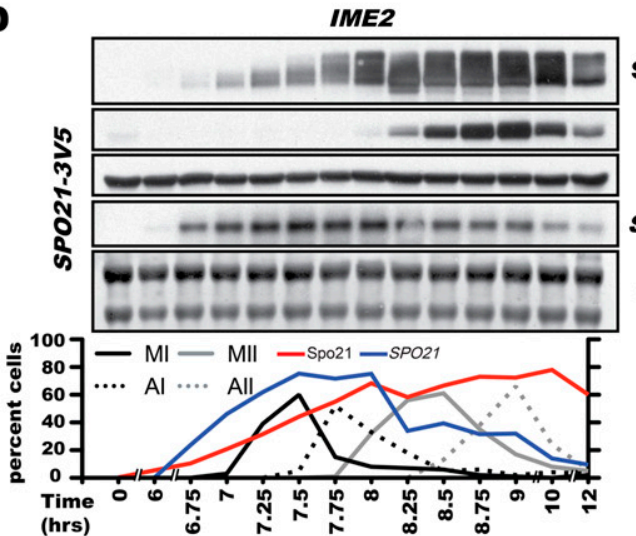

IME2 $^{\text {st }}$
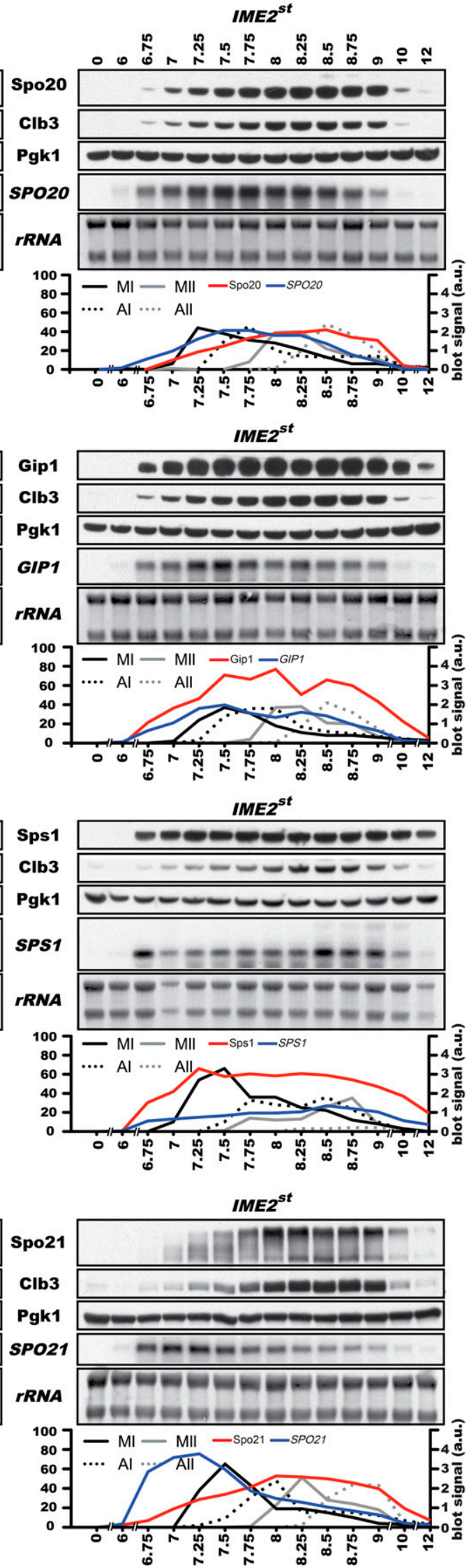

Figure 2. Ime 2 mediates the translational control of a gene cluster during meiosis I. Cells carrying the GAL4.ER and $p G A L-N D T 80$ alleles were induced to sporulate as described in Figure 1A. Clb3-3HA protein (red) and CLB3 RNA (blue) levels and meiotic progression were determined at the indicated times. In addition, SPO20 (A27537 and A29215) (A), GIP1 (A28121 and A29128) (B), SPS1 (A28127 and A28829) (C), and SPO21 (A30047 and A30572) (D) protein (red) and RNA (blue) levels were analyzed. 
A

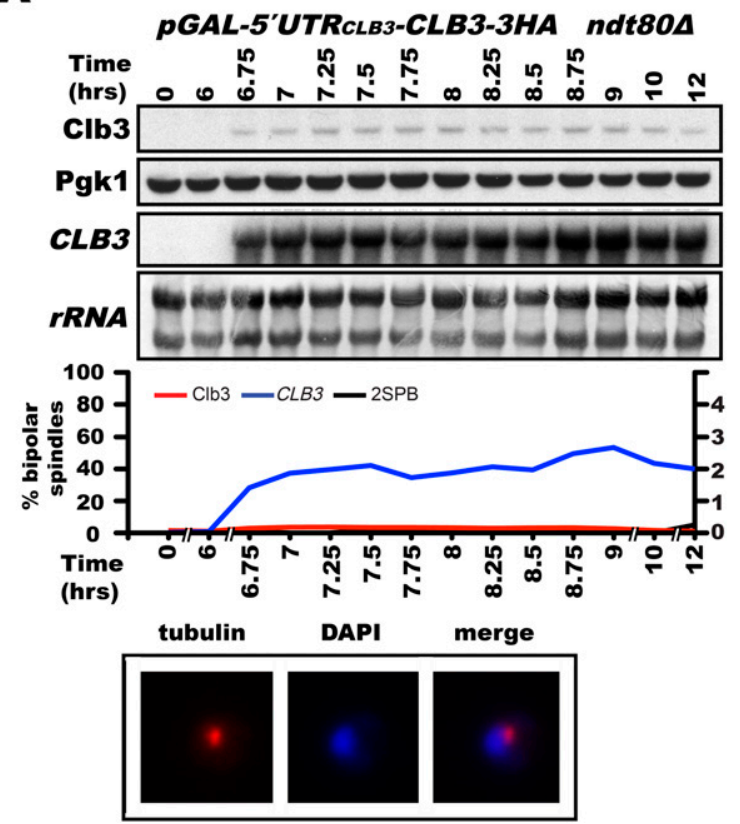

B

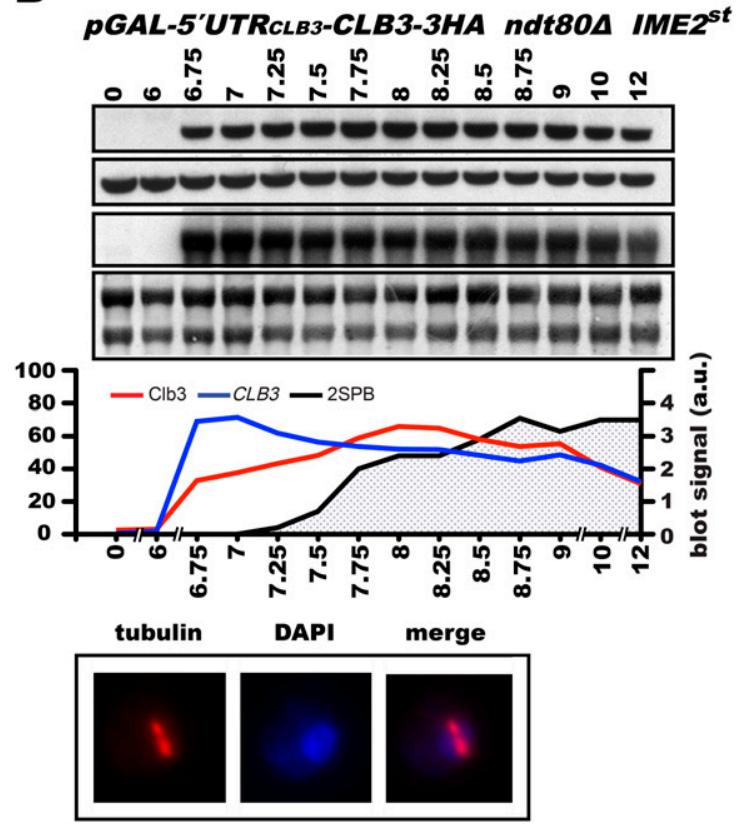

Figure 3. Translational repression is acutely responsive to Ime2 levels in prophase I-arrested cells. IME2 (A29221) (A) and IME2st (A28789) (B) strains carrying the GAL4.ER, ndt804, and $p G A L-5^{\prime} U T R_{C L B 3} C L B 3-3 H A$ alleles were induced to sporulate at $30^{\circ} \mathrm{C}$ and treated with $1 \mu \mathrm{M} \beta$-estradiol after $6 \mathrm{~h}$ to induce $C L B 3$ expression. Clb3-3HA protein (red) and CLB3 RNA (blue) levels as well as the percentage of cells harboring two spindle pole bodies (2 SPBs) were analyzed. The images show spindle (red channel) and nuclear (blue channel) morphology of representative cells that either were arrested in prophase (left) or had formed a spindle (right).

(Fig. 4D), possibly indicative of its roles at different meiotic stages.

The meiosis-specific RNA-binding protein Rim4 is an Ime2 substrate

The simplest hypothesis explaining our observations is that Ime2 either directly or indirectly inhibits the activity of a translational repressor. Given that Ime 2 is a protein kinase, we hypothesized that such a translational repressor could be an Ime2 substrate. To identify putative Ime2 substrates, we employed a previously described substrate labeling and identification method (Carlson et al. 2011). Briefly, we used the ime2-as1 allele harboring a mutation that enlarges the ATP-binding pocket. This enlarged binding pocket can accept a bulky ATP analog without affecting its substrate specificity (Bishop et al. 2000; Benjamin et al. 2003). For our analyses, we used 6Bn-ATP- $\gamma$-S in which one of the nonbridging oxygens at the $\gamma$-phosphate is replaced by a sulfur. Additionally, one hydrogen of the six-amino group has been substituted with a benzyl moiety. Indeed, immunopurified Ime2-as1, but not wild-type Ime2, can phosphorylate Histone $\mathrm{H} 1$ in in vitro kinase assays using 6-Bn-ATP- $\gamma$-S (Supplemental Fig. S5A).

We induced cells harboring the ime2-as1 allele to undergo sporulation and harvested cells at times when metaphase II cells were maximal $(2.5 \mathrm{~h}$ post-NDT80 induction). We prepared extracts and performed kinase reactions in cell lysate using the 6-Bn-ATP- $\gamma$-S analog. We then purified thiophosphate-labeled substrates and iden- tified phosphorylated substrate peptides via mass spectrometry (Supplemental Fig. S5B). This analysis revealed a list of putative substrates shown in Table 1. Among them, TEF1 encodes a translation elongation factor (Schirmaier and Philippsen 1984) that may be important for translational control of $C L B 3$. We decided to first focus on RIM4 because it encodes a meiosis-specific RNA-binding protein (Soushko and Mitchell 2000). We confirmed that Rim4 is indeed a direct substrate of Ime2 by analyzing 6-Bn-ATP- $\gamma-S$ incorporation into immunoprecipitated Rim4 from whole-cell lysate kinase assays in the presence or absence of ime2-as1 (Supplemental Fig. S6A). Rim4 immunopurified from the ime2-as1 background showed substantially more thiophosphate signal than control preparations.

\section{RIM4 is required for translational repression of CLB3}

RIM4 was discovered in a screen designed to identify proteins that regulate the expression of IME2 (Soushko and Mitchell 2000). It encodes a 713-amino-acid protein harboring two RNA recognition motifs (RRM domains). Additionally, Rim4 contains 10 low-complexity (LC) domains in its $C$ terminus that have been shown to mediate the organization of ribonucleoprotein (RNP) structures within cells (Kato et al. 2012). Deletion of RIM4 prevents cells from entering premeiotic $S$ phase (Soushko and Mitchell 2000). To investigate a possible role for Rim4 in translational repression of CLB3, we generated point mutations in the RRM domain of Rim4 (rim4F139L-3V5 and rim4-F349L-3V5) (Soushko and Mitchell 
$\mathbf{A}$
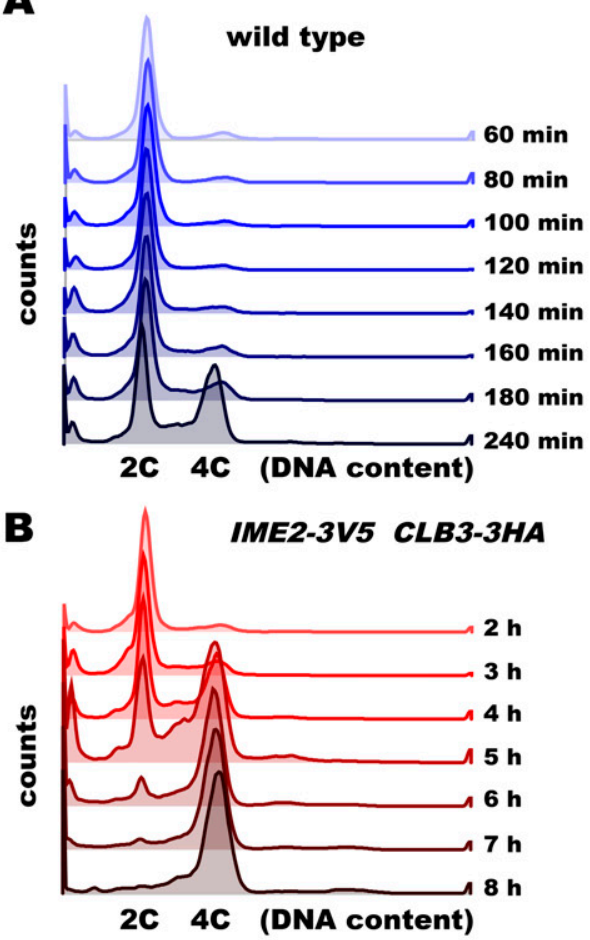

c

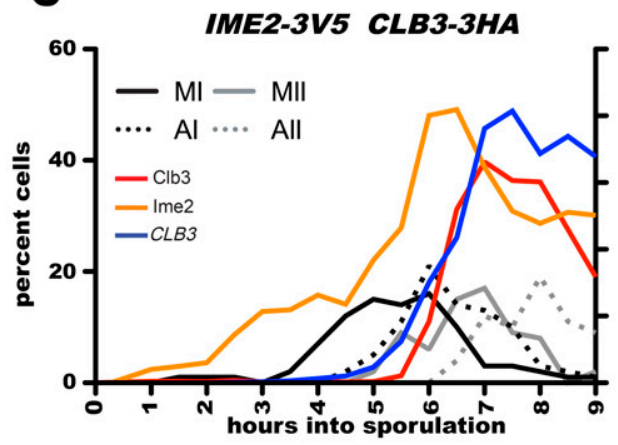

D

IME2-3V5 CLB3-3HA

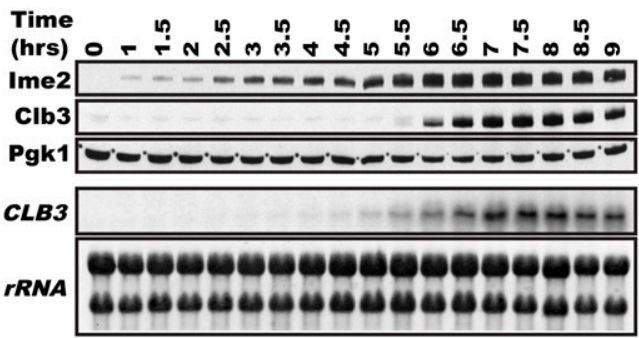

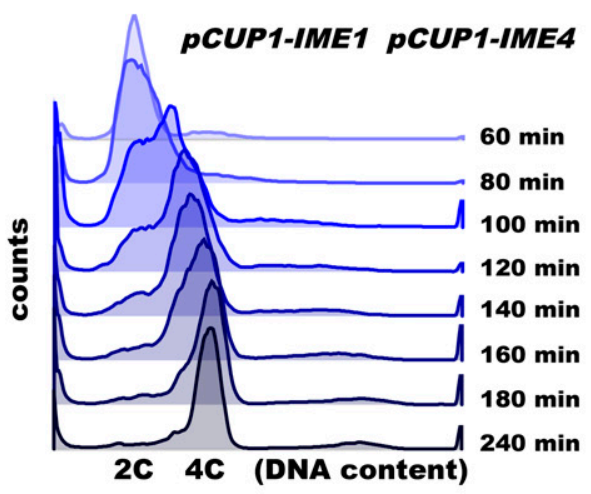
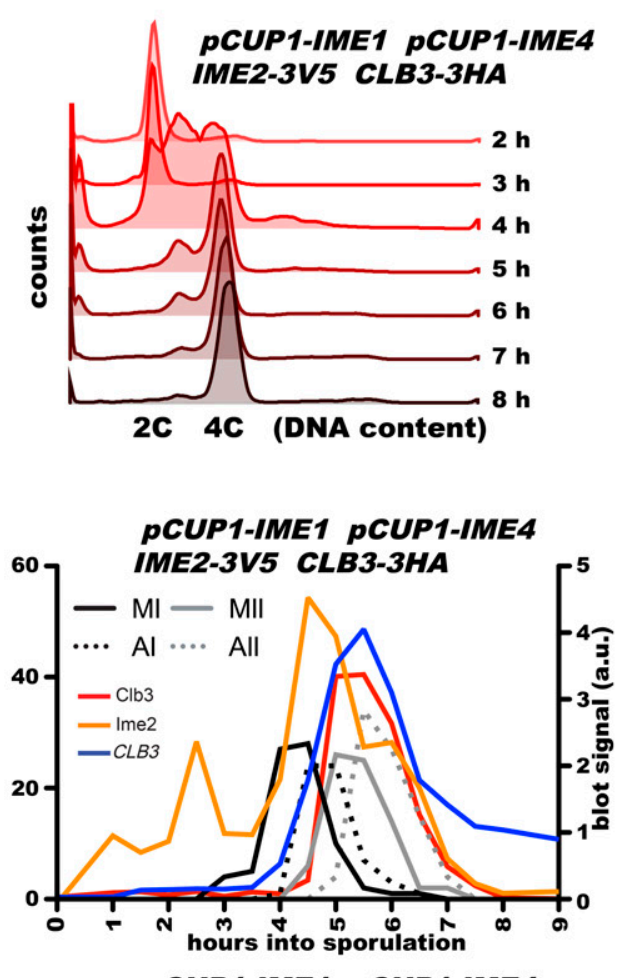

PCUP1-IME1 PCUP1-IME4 IME2-3V5 CLB3-3HA

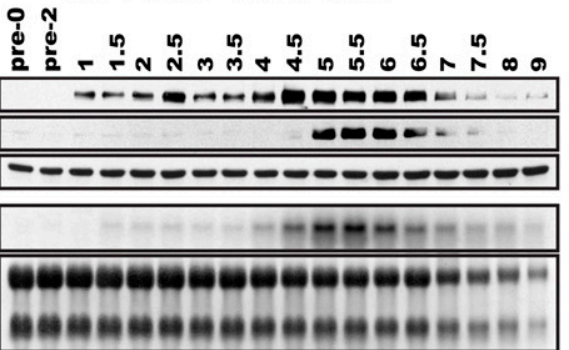

Figure 4. A novel synchronization method to analyze CLB3 translational control. (A) Wild-type (A4962) and pCUP1-IME1 $p C U P 1-$ IME4 (A33366) strains were induced to sporulate at $30^{\circ} \mathrm{C}$. After $2 \mathrm{~h}, 25 \mu \mathrm{M} \mathrm{CuSO} 4$ was added, and DNA content was determined at the indicated times. $(B-D)$ Wild-type (A33671) and pCUP1-IME1 pCUP1-IME4 (A33432) strains carrying the CLB3-3HA and IME2-3V5 alleles were induced to sporulate as described in $A$. At the indicated times, DNA content $(B)$, spindle morphology $(C)$, and Ime 2 (orange) and Clb3 (red) protein and CLB3 RNA (blue) levels were analyzed.

2000). In contrast to rim $4 \Delta$ cells, cells carrying these alleles enter sporulation and progress through the meiotic divisions, albeit with decreased efficiency
(Fig. 5A; Soushko and Mitchell 2000). Importantly, in these strains, Clb3 protein mirrored CLB3 RNA levels (Fig. 5A). 
Table 1. Proteins phosphorylated by the Ime2-as1 kinase

\begin{tabular}{llrr}
\hline Protein & \multicolumn{1}{c}{ Peptide sequence } & Start & End \\
\hline Cdc19 & R.AEVSDVGNAILDGADCVMLsGETAK.G & 313 & 337 \\
Cdc19 & K.SNLAGKPVICAtQMLESMTYNPRPTR.A & 287 & 312 \\
Clc1 & K.TEQDDILE(t)EA(s)PAKDDDEIR.D & 41 & 61 \\
Rim4 & K.LTSDGIYDDEDKDSEItIDKR.S & 326 & 346 \\
Rpn13 & K.MIGVLNNSSEsDEEESNDEK.Q & 125 & 144 \\
Tef1 & K.FVPsKPMCVEAFSEYPPLGR.F & 402 & 421 \\
Tuf1 & K.EVEDHsMQVMPGDNVEMECDLIHPTPLEVGQR.F & 386 & 417 \\
Zeo1 & K.EQAEAsIDNLKNEAtPEAEQVKK.E & 35 & 57
\end{tabular}

Peptides that were detected in each of the two technical replicates and whose tandem mass spectrometry (MS/MS) spectra passed manual validation criteria are shown (see the Materials and Methods for a detailed explanation). Peptide sequence, gene name, start/ end point of the identified peptide, and phosphorylation site (in lowercase, bold) are shown. Bracketed residues indicate phosphorylated peptides where the exact site of phosphorylation could not be definitively assigned from MS/MS data and are of equal likelihood. Curated, annotated representative spectra of the eight identified phosphorylated peptides can be found in the Supplemental Material. aPeptide was identified as having an oxidation modification in one analysis but not the other.

${ }^{\mathrm{b}}$ Peptide was identified in both analyses with and without a dioxidation modification.

To ensure that the apparent loss in CLB3 translational control in rim4-F139L-3V5 and rim4-F349L-3V5 cells was due to a specific role of the RNA-binding protein in this process rather than a consequence of poor entry and progression through the meiotic cell cycle, we examined the effects of the two RIM4 point mutants on CLB3 translation in single cells. We took advantage of the fact that (1) CLB3 is translationally repressed in prophase I-arrested cells and that (2) premature translation of the cyclin in this arrest leads to bipolar spindle formation (Fig. 3; Miller et al. 2012). We induced expression of $p G A L-5^{\prime} U T R_{C L B 3} C L B 3$ in cells arrested in prophase I due to deletion of NDT80 and identified prophase I-arrested cells using a Zip1-GFP fusion (White et al. 2004). ZIP1 encodes a component of the synaptonemal complex (SC), which forms during prophase I and can be identified as ribbon-like structures in the nucleus (Sym et al. 1993). We then determined whether these cells translated CLB3 during meiosis I using spindle formation as a readout. Whereas prophase I-arrested wild-type cells never simultaneously harbored an SC and a meiosis I spindle, a high percentage of rim4F139L-3V5 and rim4-F349L-3V5 cells did (Fig. 5B; Supplemental Fig. S6D). These results demonstrate that rim4F139L-3V5 and rim4-F349L-3V5 cells are defective in repressing CLB3 translation during prophase I. Analysis of Clb3 protein levels are consistent with this interpretation. Wild-type cells did not translate CLB3 in the prophase I arrest, but rim4F139L-3V5 and rim4F349L-3V5 cells did (Fig. 5B). Importantly, spindle formation in the rim4 mutant background is CLB3-dependent. When $p G A L-5^{\prime} U T R_{C L B 3} C L B 3$ is not induced in prophasearrested rim4F139L-3V5 cells, almost no bipolar spindles are observed, and no Clb3 protein is produced (Supplemental Fig. 6SB,C) We conclude that RIM4 is required for translational repression of CLB3.

\section{Rim4 binds to the CLB3 5' UTR}

Rim4 harbors two RRM domains, which have been shown to be critical for RNA binding in other proteins and which we showed to be essential for translational repression of $C L B 3$ during meiosis I (Fig. 5A,B). To test the possibility of a direct interaction between the CLB3 mRNA and Rim4, we performed extract-binding studies. We transcribed the CLB3 5' UTR along with three controls in vitro: the CLB3 5' UTR with a 25-nucleotide (nt) deletion in a region critical for translational control (CLB3-425) (data not shown), the 248-nt CLB1 5' UTR, and a 28-nt RNA containing an iron response element (IRE). We chose these controls because CLB1 is translated efficiently in all meiotic stages (Carlile and Amon 2008), and the IRE is a well-characterized motif involved in $5^{\prime}$ UTR-mediated translational control (Gray and Hentze 1994). We then coupled these RNAs via a biotin group to streptavidin beads and assayed the ability of the RNA to pull down Rim4-3V5 from extracts prepared from prophase I-arrested cells. Rim4-3V5 bound to the full-length CLB3 5' UTR but not control UTRs (Fig. 5C). We were not able to assess the ability of Rim4 to bind the CLB3 5' UTR during meiosis II or in the IME2st background because Rim4 protein levels decline dramatically upon completion of meiosis I, and Rim4 is highly unstable in extracts prepared from IME2st cells (see below). We conclude that Rim4 directly or indirectly binds to elements within the CLB3 5' UTR critical for translational control of $C L B 3$.

\section{Rim4 is associated with translationally repressed mRNAs}

Rim4 is an abundant protein and might bind to mRNAs other than CLB3. To identify other mRNAs that associate with Rim4, we immunoprecipitated Rim4 and analyzed the coprecipitated mRNAs using microarrays (RIP-chip). In one series of experiments, we immunoprecipitated tagged Rim4 (RIM4-3V5) or, as a control, a rim4-F139L3V5 mutant, which very likely has compromised RNAbinding activity, and compared the enrichments of all mRNAs in these two immunoprecipitates (Fig. 5D). We also compared an immunoprecipitation of either tagged RIM4-3V5 or rim4-F139L with an immunoprecipitation of an untagged RIM4 strain (Supplemental Fig. S6E,F).

For statistical analyses, we focused on several preselected gene sets. Genes were preselected mainly on the 


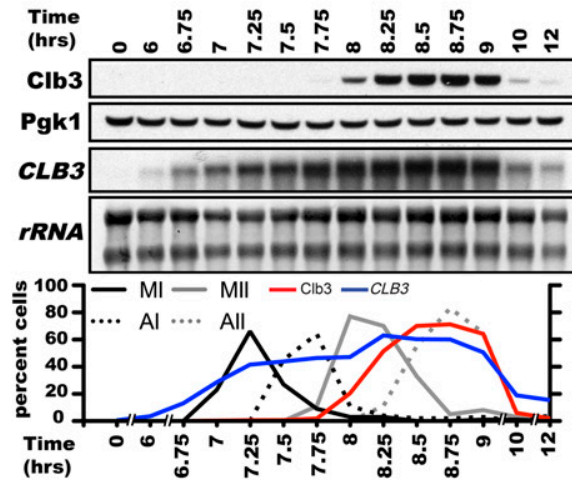

B

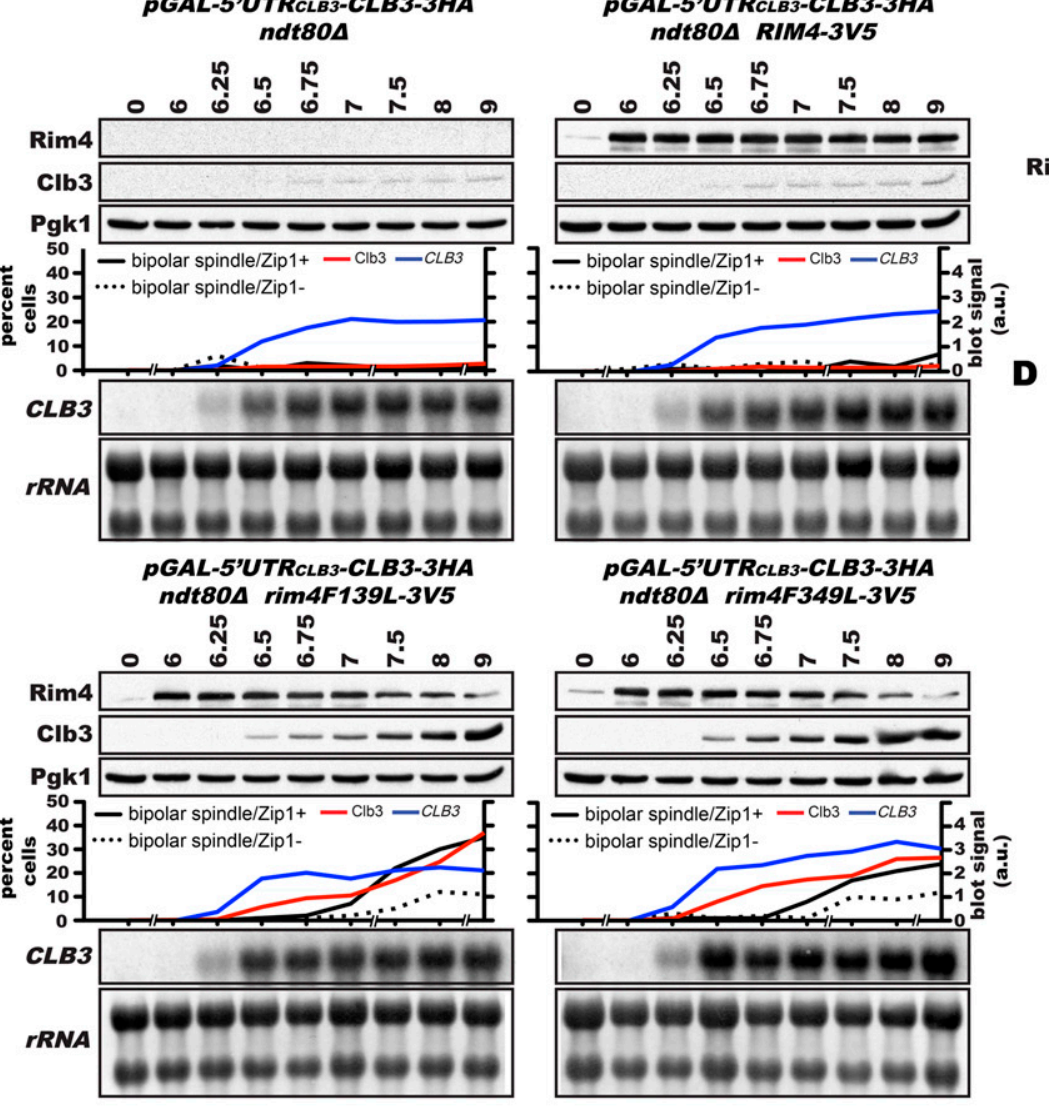

\section{C}

D

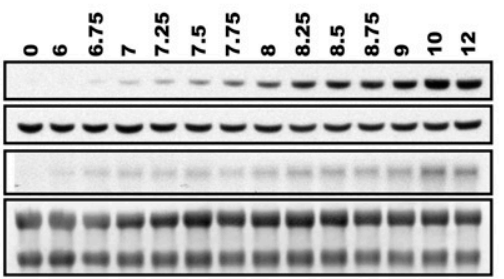

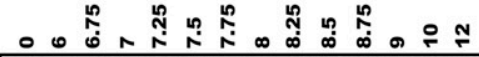
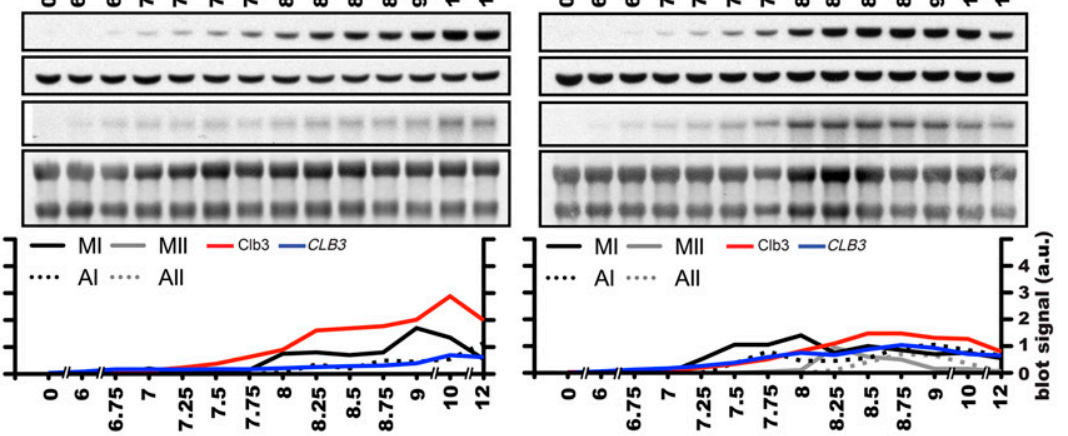

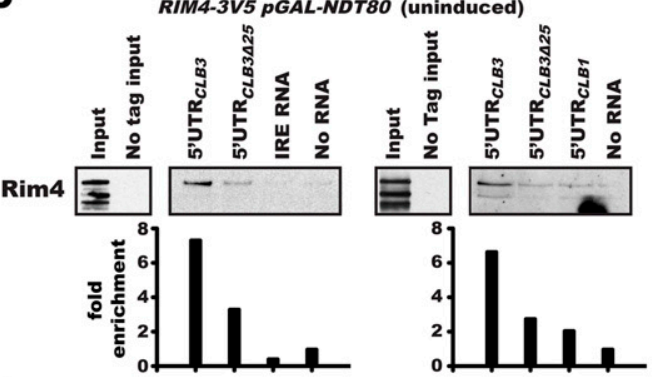

RIM4-3V5/rim4F139L-3V5

- $C L B 3$

- SPO20, SPS1, GIP1, YSP2, YFL012W

Translationally repressed genes that co-cluster with $A M A 1$ Negative control pool

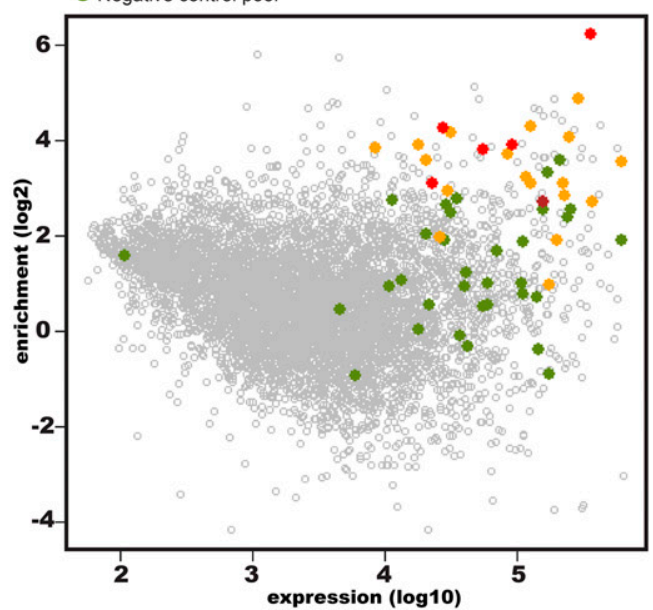

Figure 5. Rim4 regulates translation of the IME2-regulated gene cluster. (A) Wild-type (A15055), rim4F139L-3V5 (A31420), and rim4F349L-3V5 (A31421) strains carrying the GAL4.ER, $p G A L-N D T 80$, and CLB3-3HA alleles were sporulated at $30^{\circ} \mathrm{C}$. After $6 \mathrm{~h}$, cells were released from the prophase I arrest, and Clb3 protein (red) and RNA (blue) levels as well as spindle morphology were determined at the indicated times. (B) Wild-type (A29221), RIM4-3V5 (A32978), rim4F139L-3V5 (A33322), and rim4F349L-3V5 (A33429) strains carrying the GAL4.ER, ndt804, ZIP1-GFP, and $p G A L-5^{\prime} U_{T R R_{C L B} C L B 3-3 H A}$ alleles were grown as in $A$ to analyze Rim4-3V5 and Clb33HA protein (red) and CLB3 RNA (blue) levels. Spindle morphology as well as the presence or absence of Zip1 were determined (see Supplemental Fig. S6D for classification criteria). (C) Rim4 binds the CLB3 5' UTR. Extracts from GAL4.ER, pGAL-NDT80, RIM4-3V5, and CLB3-3HA cells (A30868) arrested in prophase I were incubated with in vitro transcribed, 3' biotinylated RNAs conjugated to streptavidin Dynabeads. Beads were recovered, and RNase elution was performed to release bound factors (Michlewski and Caceres 2010). Shown is the amount of Rim4 purified using each RNA bait. Quantifications are shown as fold enrichment over the no-RNA control. (D) Rim4 binds the IME2-regulated gene cluster mRNAs. RIM4-3V5 (A30868) and rim4-F139L-3V5 (A31420) strains carrying the GAL4.ER, $p G A L-N D T 80$, and CLB3-3HA alleles were sporulated at $30^{\circ} \mathrm{C}$. After $6 \mathrm{~h}$, cells were released from the prophase I arrest, and $800 \mathrm{~mL}$ of cell pellets was collected at meiosis I $(7.5 \mathrm{~h})$. Rim 4 was purified from extracts using anti-V5 agarose and eluted with 2.5 $\mathrm{mg} / \mathrm{mL}$ V5 peptide. RNA was extracted from the eluate and converted to cDNA and then to cRNA. Immunoprecipitated RNA from both RIM4-3V5 and rim4-F139L-3V5 was labeled with Cy3, and reference RNA was labeled with Cy5. Total RNA extracted from RIM4$3 V 5$ cells in meiosis I was used as the reference RNA. Cy3- and Cy5-labeled RNA was hybridized to an expression array. Shown is a mathematical comparison of RIM4-3V5 versus rim4-F139L-3V5 normalized using the common reference RNA. The Y-axis shows the $\log _{2}$ enrichment of each gene (RIM4-3V5/rim4-F139L-3V5), and expression level is shown on the $X$-axis. CLB3 is highlighted in dark red; GIP1, SPS1, YSP2, YFL012W, and SPO20 are highlighted in red; translationally repressed genes that cocluster with AMA1 are highlighted in yellow; and a negative control pool of nontranslationally repressed, highly expressed genes is highlighted in green. 
basis of whether they showed evidence of translational repression in meiosis based on the ribosome profiling footprint data of Brar et al. (2012). Two sets of genes showed translational repression in this analysis. One cluster comprised the translationally repressed genes CLB3, SPO20, YSP2, YFL012W, GIP1, and SPS1 (Brar et al. 2012). The second cluster included the meiotic cell cycle regulator $A M A 1$ and 10 other genes that appear to be translationally repressed (Supplemental Material; Brar et al. 2012). Two sets of negative controls were selected; the first set was comprised of seven highly expressed $G A L$ genes that are not meiotic genes but are highly expressed in our strain because of induction by GAL4.ER. The second set was comprised of 26 meiotic genes that are very strongly expressed immediately after induction of pGAL-NDT80 but show robust, immediate ribosome footprints. These 26 genes form a strong cluster with each other.

As a group, the translationally repressed genes were enriched relative to the negative controls in the RIM4$3 V 5$ versus rim4-F139L-3V5 experiment, as expected for Rim4-associated mRNAs (Fig. 5D). This was confirmed by the finding that there are statistically significant differences between each set of translationally repressed genes compared with the negative control genes. For either of the sets of repressed genes compared with either of the sets of negative controls, the difference was significant, with a $P$-value $<0.01$. For the pooled repressed genes (i.e., the two clusters considered together) compared with the pooled negative controls, the $P$-value was $<0.0001$. These results are most consistent with the idea that Rim4 is associated with not only CLB3, but also its coclustering genes as well as many or all of the translationally repressed genes coclustering with $A M A 1$. Notably, SPO20 had the highest enrichment score of any gene. Translationally repressed genes were also significantly enriched relative to negative controls in the RIM4-3V5 versus RIM4 (untagged) experiment (Supplemental Fig. S6E). Interestingly, translationally repressed genes were significantly depleted in rim4-F139L-3V5 cells relative to untagged control cells (Supplemental Fig. S6F). This raises the possibility that Rim4 could affect the localization, stability, and/or transcription of the mRNAs to which it binds.

We note that there are other genes that appear to be enriched in the Rim4 immunoprecipitates but are not members of the preselected groups. Some of these show various degrees of translational repression, but others do not. Further experiments will be required to determine whether these mRNAs are genuinely associated with Rim4.

\section{Ime2 regulates $\mathrm{Rim} 4$ abundance}

What is the relationship between Ime2 and Rim4 in translational control? The simplest hypothesis is that IME2 interferes with Rim4 function during meiosis II. We tested the hypothesis that IME2 regulates Rim4 abundance. Inhibition (via the ime2-as1 allele + 1-NA-PP1 inhibitor) of Ime 2 upon release from a prophase I block led to the persistence of Rim4 protein throughout meiosis II. In contrast, the protein declined prior to meiosis II in control cultures. This is best seen in single-cell analyses. Rim4 persisted beyond meiosis I in cells lacking IME2 function (Fig. 6A,B). Particularly striking was the fact that $>50 \%$ of anaphase II cells retained Rim 4 when Ime 2 was inhibited. Importantly, inactivation of Ime2 led to not only the persistence of Rim4 well into meiosis II, but also inhibition of CLB3 translation during meiosis II (Fig. 6C). We conclude that IME2 is required for the decrease in Rim4 protein levels during early stages of meiosis II and translation of CLB3 during meiosis II.

If IME2 acts through RIM4 to relieve translational repression of $C L B 3$, inactivating RIM4 should restore $C L B 3$ translation to Ime2-inhibited cells. Indeed, CLB3 was efficiently translated throughout meiosis in rim4F139L cells irrespective of whether Ime2 was active (Fig. 6D). We noted that the rim4F139L protein was less abundant than wild-type protein (Fig. 6C,D; Soushko and Mitchell 2000) and not significantly stabilized in ime2-as1 cells, suggesting that the F139L substitution leads to destabilization of the protein.

To further test the idea that Ime2 controls Rim4 abundance, we examined the consequences of expressing IME2st on Rim4 protein levels. Rim4 protein levels declined prematurely in IME2st-expressing cells (Fig. 7A,B). This premature decline is best seen when analyzing Rim4 protein in individual cells. Whereas Rim4 persists into metaphase II in $64 \%$ of wild-type cells, in cells expressing the IME2st allele, Rim4 was not detectable in metaphase II cells and was detectable in only $36 \%$ of anaphase I cells (Fig. 7C). We conclude that IME2 regulates $C L B 3$ translation at least in part by regulating Rim4 protein levels. We further note that IME2st affected not onlyRim 4 abundance, but also Rim4 mobility in SDSPAGE (Fig. 7A). These slower-migrating forms of Rim4 are due to phosphorylation (data not shown), and their appearance in cells with Ime2st is consistent with our observation that Rim4 is an Ime2 substrate.

Our mass spectrometry analysis identified Thr342 of Rim4 to be phosphorylated by Ime2. Mutation of this residue to alanine, however, did not affect CLB3 translation (data not shown). Similarly, mutation of the lone Ime 2 consensus site in Rim4 (S93A) to alanine did not affect the translation efficiency of CLB3 either (data not shown). Clearly, Rim4 control by Ime2 is more complex, and a more thorough analysis of the Rim4 phosphorylation will be required to elucidate the impact of Ime2 phosphorylation on Rim4 abundance and activity.

How does the premature decline in Rim4 protein levels affect CLB3 translation? The correlation between Rim4 decline and Clb3 protein accumulation was difficult to assess by immunoblot analysis because loss of Rim4 in only a small fraction of cells leads to a dramatic increase in Clb3 protein levels. Indeed, from the immunoblot analysis shown in Figure 7A, it appears that Clb3 protein begins to accumulate well before Rim 4 protein declines. We therefore compared the decline in Rim4 signal intensity in single cells and compared that with the accumulation of Clb3 protein as determined by immunoblot 


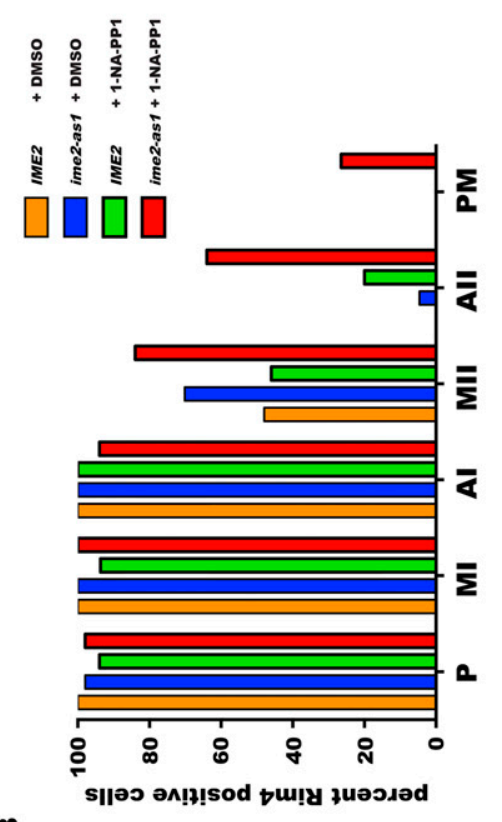

m

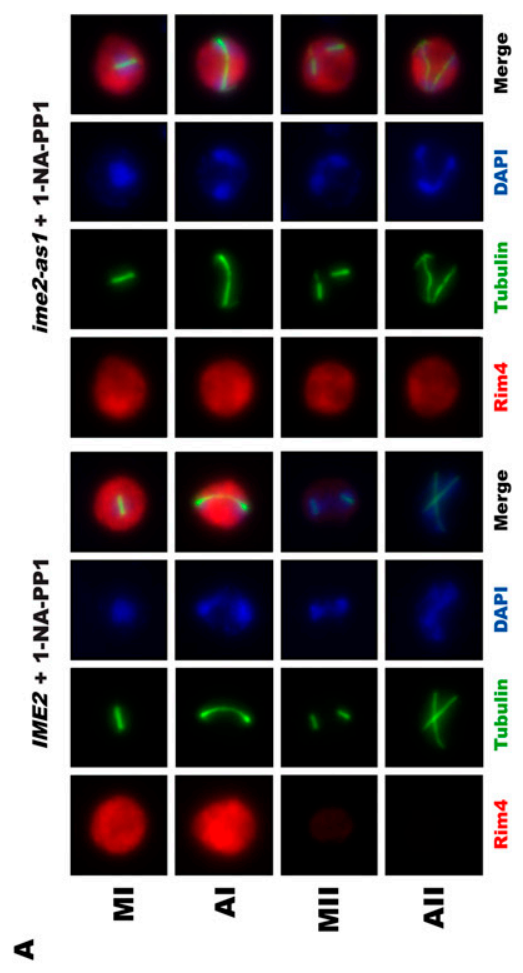

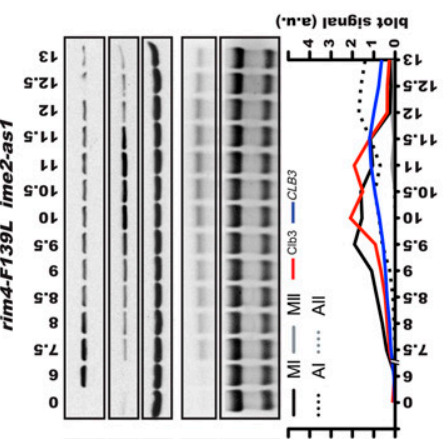

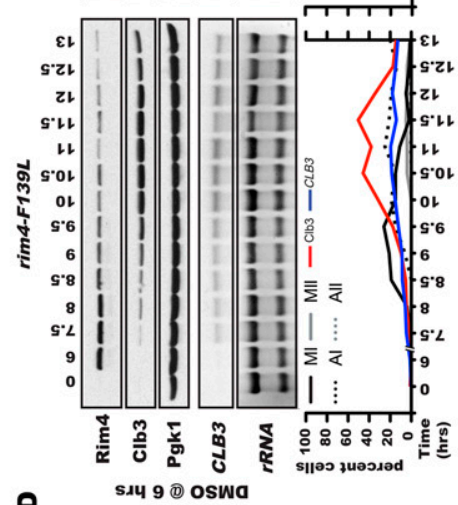

อ
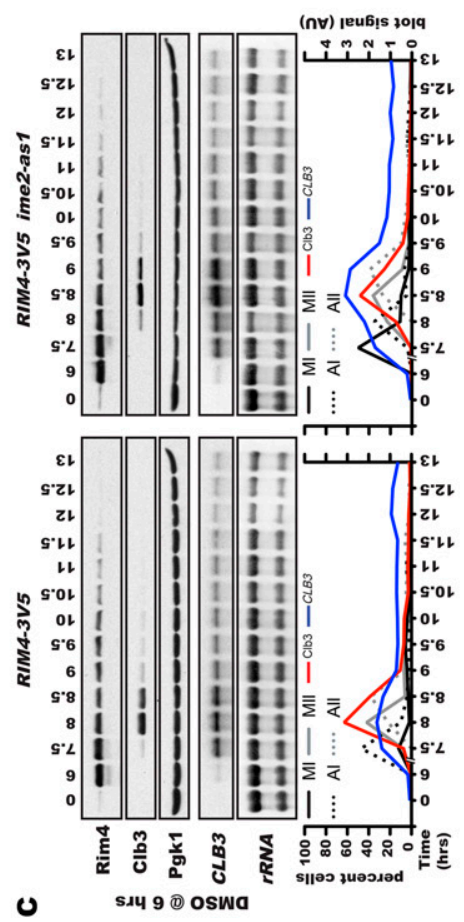

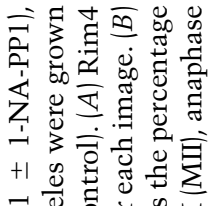

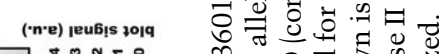
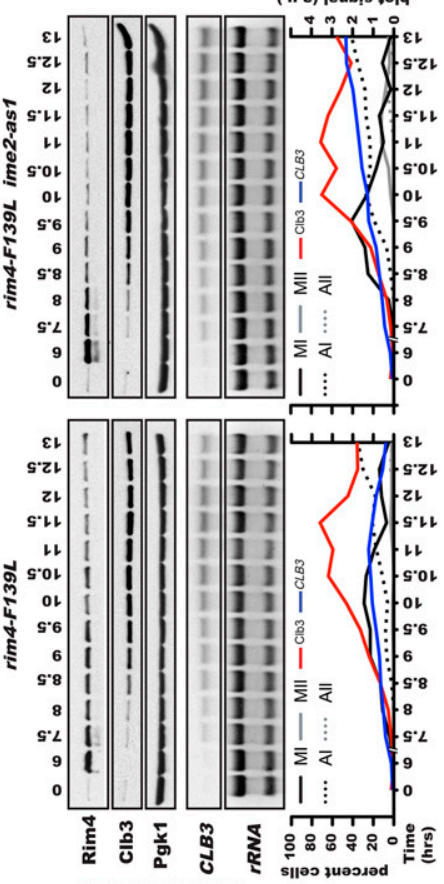

SגY 9 (1) Ldd- VN-L
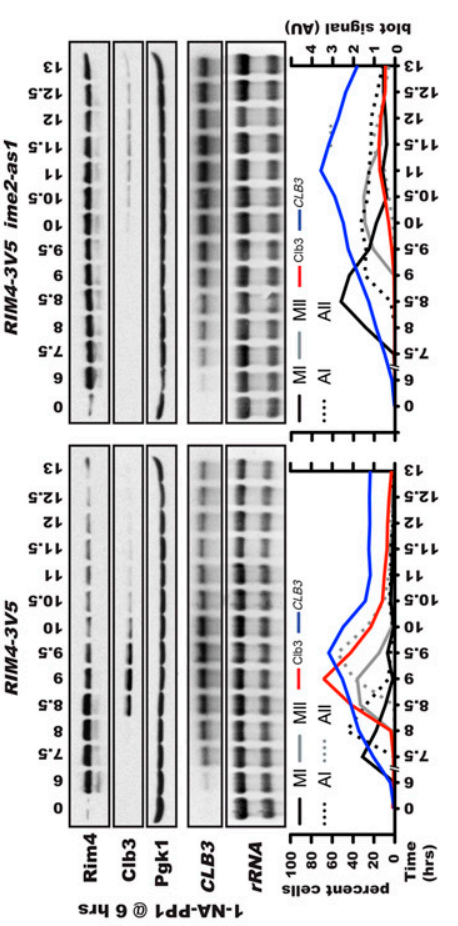

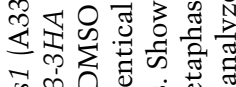

तै के ขै

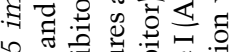
के $\infty$ ज्ञ की

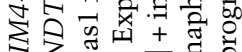
व

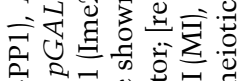

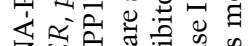

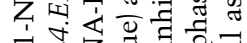

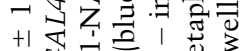

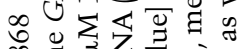

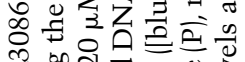

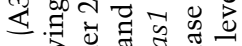

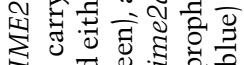
« कि

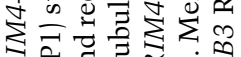

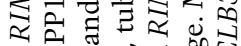

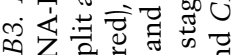
प् कि

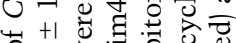

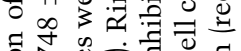
.

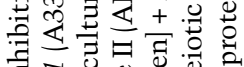

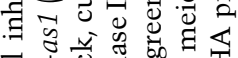
สี ข่ํㅡㄹ

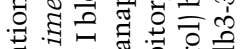

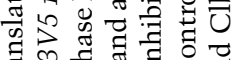

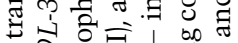

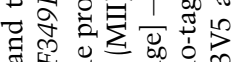

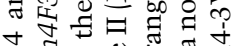

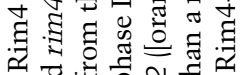

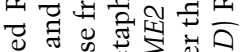

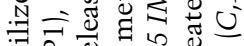
क्षे

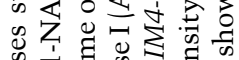

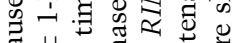

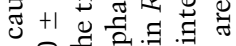

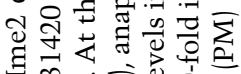

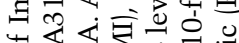

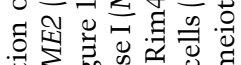
i 50000

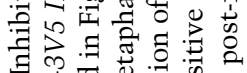

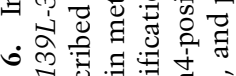

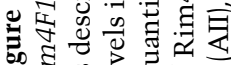

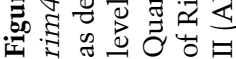


Berchowitz et al.

A

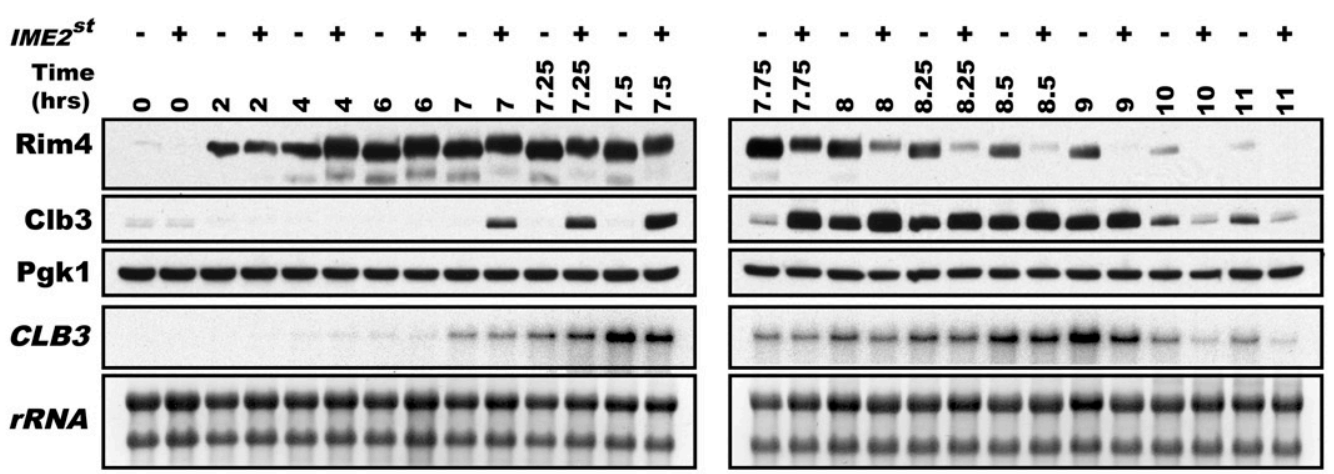

B
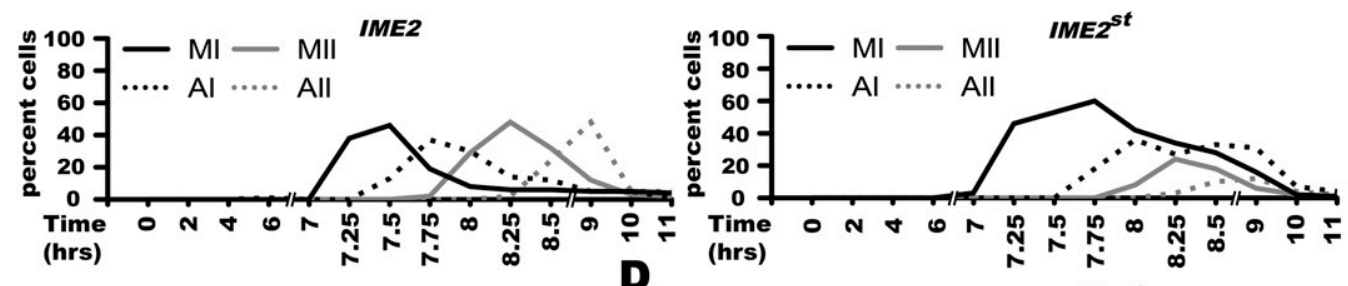

C
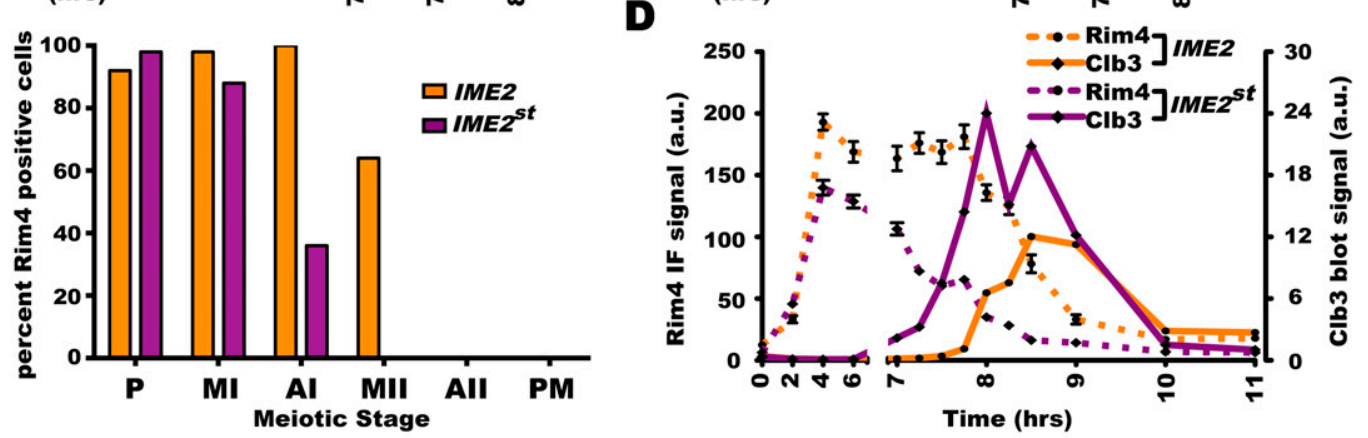

E

IME2

F

IME2 ${ }^{s t}$

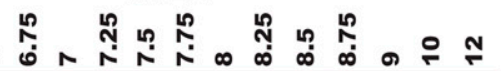
0 - 0 O
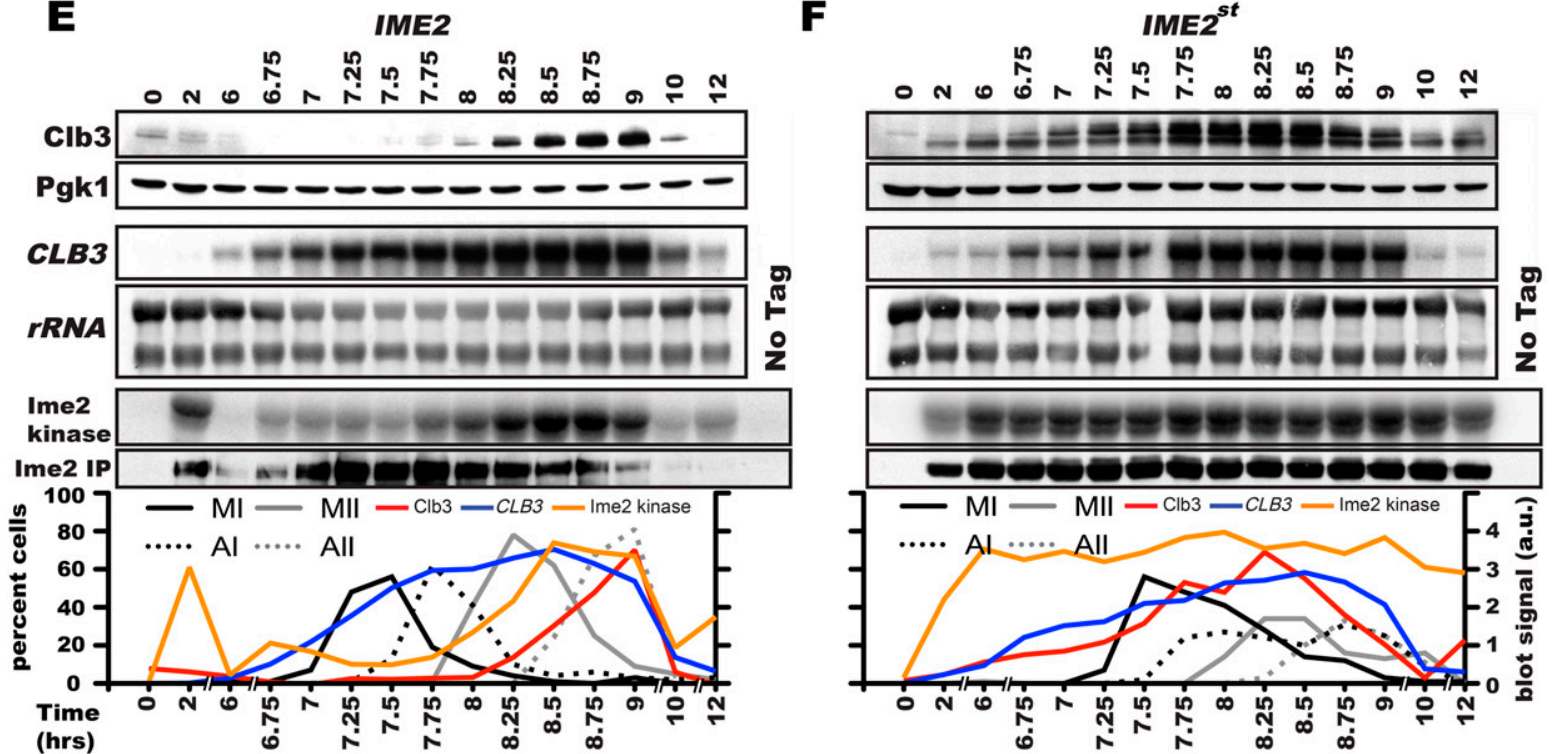

Figure 7. Ime2 kinase activity is up-regulated in meiosis II and affects Rim4 abundance. $(A-C)$ Expression of hyperactive Ime2 affects Rim4 mobility. IME2 (A30868) and IME2st (A33027) strains carrying the GAL4.ER, pGAL-NDT80, CLB3-3HA, and RIM4-3V5 alleles were induced to sporulate as described in Figure 1A. Rim4-3V5 and Clb3-3HA protein and CLB3 RNA levels $(A)$, meiotic progression $(B)$, and Rim4 abundance in individual cells $(C)$ were determined at the indicated times. $(D)$ Shown is intensity of Rim4 signal by immunofluorescence (dashed lines) and the intensity of $\mathrm{Clb3}$ by immunoblot quantification (solid lines) over the meiotic time course in the IME2 (orange) and IME2st (purple) backgrounds. $(E, F)$ IME2-3V5 (A27742) (E) and IME2st-3V5 (A28342) (F) strains carrying the GAL4.ER, $p G A L-N D T 80$, and CLB3-3HA alleles were induced to sporulate as described in Figure 1A. Ime2 kinase activity (orange), Ime2 immunoprecipitation, Clb3-3HA protein (red), and CLB3 RNA (blue) levels and meiotic progression were determined at the indicated times. 
analysis. This analysis revealed that the decline in Rim4 levels is anti-correlated with Clb3 protein accumulation (Fig. 7D). We conclude that Ime 2 affects Rim 4 abundance, thereby alleviating Rim4-mediated translational inhibition during meiosis II. Our findings are most consistent with the idea that Ime2 triggers the degradation of Rim4. Whether this is the only mechanism whereby Ime2 affects Rim4 activity remains to be determined.

\section{Ime2 kinase activity is low during meiosis I}

Why does Ime2 trigger a decline in Rim4 levels during meiosis II but not meiosis I? To address this question, we examined Ime2 kinase activity in cells progressing through the meiotic divisions upon release from a prophase I block. As observed previously (Benjamin et al. 2003), Ime2 kinase activity is high as cells enter premeiotic S phase (2-h time point) (Fig. 7E) but was low in the prophase I arrest (6-h time point) (Fig. 7E) due to low levels of Ime2 protein in the immunoprecipitate. We repeatedly observed that although Ime2 protein was present in extracts prepared from prophase I cells, the protein was unstable, leading to low-level recovery in immunoprecipitates. The basis for this instability is unknown at present.

Upon release from the prophase I block, Ime2 protein was more stable and could readily be recovered in immunoprecipitations (Fig. 7E). However, Ime2-associated kinase activity remained low throughout meiosis I. In contrast, Ime2 kinase was highly active during meiosis II. Our results indicate that Ime2 kinase activity is cell cycle-regulated and low during meiosis I. This downregulation of Ime2 kinase activity could explain why Ime2 does not interfere with RIM4-mediated translational repression of $C L B 3$ during meiosis I. Consistent with this idea is the finding that the IME2st allele produces ample kinase activity during meiosis I and results in CLB3 translation during meiosis I (Fig. 7F). We conclude that down-regulation of Ime2 during meiosis I is an important aspect of translational repression during this meiotic stage.

\section{Discussion}

We previously reported the identification of translational control operating on the B-type cyclin CLB3 and its importance for establishing the meiotic chromosome segregation pattern (Carlile and Amon 2008; Miller et al. 2012). Here we show that several other genes, all important for late meiotic events, are regulated in a manner similar to that of CLB3 such that their mRNAs remain poised in an inactive state until entry into metaphase II. This is presumably when the proteins they encode are needed for meiosis II and/or spore morphogenesis. Furthermore, our studies show that Ime2 regulates the translation of this cluster of meiosis II translated genes, indicating that the mechanism of translational control operative on this gene cluster is the same. However, it is interesting to note that although very similar, the timing of translation is not identical among the IME2-regulated gene cluster. For example, GIP1 translation occurs concomitantly with that of CLB3, but that of SPO2O and SPS1 occurs somewhat later (Fig. 2). Thus, subtle differences in translational regulation may exist, the basis of which will be interesting to determine.

Although the importance of translational control in gametogenesis has been well established in multicellular organisms, its role in unicellular organisms such as budding yeast has only recently been established (Nakamura and Seydoux 2008; Brar et al. 2012). A recent study by Brar et al. (2012) revealed that translational control is much more pervasive during sporulation than previously assumed. Highlighting the dynamics of translational efficiency during meiosis, $25 \%$ of genes expressed during the meiotic program exhibit a threefold range in the ratio of total mRNAs to ribosome-occupied mRNAs. Moreover, the $5^{\prime}$ UTRs of $\sim 200$ genes increase in length during gametogenesis, suggesting that $5^{\prime}$ UTRmediated translational control is an important control mechanism operating during budding yeast gametogenesis. Our detailed studies on CLB3 support this view. Translational control of this gene is predominantly, if not solely, mediated by the 5' UTR. This stands in contrast to all reports of gametogenic translational control in multicellular organisms that show that $3^{\prime}$ UTR elements are the critical determinants of translational regulation.

\section{RIM4 is a message-specific regulator of translation} in meiosis

Our data show that the meiosis-specific RNA-binding protein Rim4 represses CLB3 translation during meiosis I. Our data further indicate that Rim4 directly or indirectly interacts with the $5^{\prime}$ UTR of CLB3 to mediate this regulation. These observations raise the question of how Rim4 represses translation of the mRNAs to which it binds. One possibility is that binding of Rim 4 to a target 5' UTR inhibits 43S recruitment, which is seen in ferritin translational control (Gray and Hentze 1994). A nonmutually exclusive possibility is that 60S subunit joining is affected, as is seen in LOX translational control (Ostareck et al. 2001). Rim4 could also affect translation by inhibiting the interactions between initiation factors at the $5^{\prime}$ cap, such as the association of eIF4E with eIF4G. This type of regulation has been described in many systems, notably in the translational repression of Cyclin B1 mRNA in Xenopus meiosis by the CPEB-Maskin complex (Groisman et al. 2000). Since ribosomal profiling data show that $C L B 3$ mRNA is devoid of ribosomes in meiosis I (Brar et al. 2012), Rim4 most likely regulates translation at the level of initiation.

RIM4 is not only needed for CLB3 translational repression, but is also essential for entry into gametogenesis. Cells lacking RIM4 fail to enter sporulation because they cannot express IME2 (Soushko and Mitchell 2000). Indeed expression of a stabilized version of IME2 partially suppresses this requirement. How RIM4 brings about Ime2 expression is not understood, although Soushko and Mitchell (2000) speculated that Rim4 may bind to glutaminyl tRNA, which is a critical regulator of the 
nitrogen limitation response mediating sporulation (Murray et al. 1998). Rim4 could recognize this molecule and subsequently transmit information to downstream targets such as IME2. Based on our findings, we propose that Rim4 inhibits the translation of some factor that inhibits Ime2 expression and/or activity. It is also possible that RIM4 functions as a translational activator in the context of entry into sporulation. Our genome-wide analyses of RNAs that bind Rim4 further identified $A M A 1$ and 10 other genes whose translation is restricted to late stages of sporulation as Rim4-assocaited RNAs. Although the importance of RIM4 in regulating the translation of these genes has not yet been established, it is tempting to speculate that Rim 4 controls the translation of many RNAs at different stages of meiosis, serving as a mediator of many different translational control mechanisms. The identification of the RNAs that bind Rim4 at different stages of sporulation and of Rim4interacting proteins will address how Rim 4 participates in the control of multiple classes of translationally regulated RNAs.

In addition to directly affecting access of the translation machinery to the target mRNA, Rim4 could also regulate the translational efficiency of its targets via sequestration of mRNA into translationally inactive RNPs. We did not observe focal Rim4 staining, but because Rim4 is such an abundant protein, it is possible that these foci escaped detection. Rim4 contains 10 LC domains. Such domains mediate the (reversible) formation of RNPs (Kato et al. 2012; Weber and Brangwynne 2012). Thus, Rim4 is an ideal candidate for assembling into non-membrane-bound RNP structures. RNP structures, including P-bodies, P-granules, and germ granules, have been described in germ cells of many animal species and shown to regulate the translation of key regulators of germ cell development and early embryonic patterning (Schisa 2012). Our results indicate that translational control of mRNAs is a much more widespread regulatory tool in germ cell development than previously appreciated and is perhaps an ancient and integral aspect of the evolution of sexual reproduction.

Finally, we note that although Rim4 clearly regulates translation of some of its targets, it is also possible that Rim4 controls functions other than translation through interaction with other regions of target RNAs. We note that in Schizosaccharomyces pombe, the RNA-binding protein Mmil can promote mRNA degradation or inhibit splicing, depending on where in the mRNA it binds (Chen et al. 2011).

\section{Ime2 induces translation of meiosis II genes}

The role of Ime2 in premeiotic S phase entry is well understood. The protein kinase triggers the degradation of the S-phase CDK inhibitor Sic1, thereby initiating DNA replication. Previous studies also showed that IME2 is required for efficient entry into meiosis II, but its function during this meiotic transition was not understood (Benjamin et al. 2003). Our data indicate that one function of the kinase is to trigger translation of many genes important for meiosis II and spore formation. Dysregulation of Ime2 by either stabilization or inhibition affects translation in a manner consistent with its role as a translational activator. Our studies further identified the putative RNA-binding protein Rim4 as a key target of Ime 2 in translational control. We propose that genes within the IME2-regulated cluster are translationally repressed during meiosis I through their association with Rim4. We suggest that Ime2 phosphorylates Rim4 and perhaps other proteins involved in translational repression, thereby neutralizing their translation inhibitory activities.

How Ime2 regulates Rim4 activity remains to be determined. Our data indicate that Ime2 regulates the abundance of Rim4 during meiosis. The simplest interpretation of this observation is that Ime2-dependent phosphorylation of Rim4 targets the protein for degradation, but effects on RIM4 transcription, translation, and/ or activity cannot be excluded at this point. We should further note that irrespective of the mechanism whereby Ime 2 controls Rim4 abundance, this mechanism is operative only during the meiotic divisions and not during entry into gametogenesis. As cells enter sporulation, Ime 2 activity and Rim 4 protein levels are high. This indicates that the mechanism whereby Ime2 controls Rim4 abundance during the meiotic divisions is not operative during entry into sporulation. Interestingly, expression of a number of genes involved in ubiquitinmediated protein degradation (e.g., UBA3, HUL4, UBC5, and $U B C 11$ ) is under NDT80 control. It will be interesting to determine whether ubiquitination factors control Rim4 levels.

Finally, we note that Ime2 may affect not only Rim4 abundance, but also Rim 4 activity. Ime 2 phosphorylation could reduce the binding affinity of Rim4 to its targets. RNA-binding proteins generally harbor a strong positive charge. Perhaps phosphorylation events on Rim4 neutralize its charge, lowering its RNA-binding affinity.

\section{The central regulator of gametogenesis Ime2 is subject to complex regulation}

Previous studies and this work highlight the multiple essential functions of Ime2 in gametogenesis (Smith and Mitchell 1989; Dirick et al. 1998; Benjamin et al. 2003; Holt et al. 2007). It is thus not surprising that the kinase itself is under complex control. First, IME2 transcription is confined to sporulation (Smith and Mitchell 1989). Second, our data suggest that the stability of the protein changes during gametogenesis. The protein appears less stable during premeiotic $S$ phase and prophase I, as judged by our inability to recover the protein in immunoprecipitations. Ime2 kinase activity is also regulated. Ime2 kinase activity is high as cells enter premeiotic $S$ phase and during meiosis II but is low during meiosis I even though protein levels are high at this time. The mechanism that inhibits Ime2 activity during meiosis I is not known. It is interesting, however, to note that the expression pattern of the positive regulator of Ime2, IDS2, matches Ime2 activity levels during sporulation. IDS2 
was identified in a screen for genes that, when inactivated, repress the toxicity of mitotically expressed Ime2 (Sia and Mitchell 1995). Ids2 is degraded upon entry into sporulation but resynthesized during the meiotic divisions (Brar et al. 2012). It is also possible that Ime2, like CDKs, has inhibitors. Identification of meiosis I-specific Ime2-binding proteins may identify such Ime2 kinase inhibitors.

\section{Translational control in the germline-an ancient mechanism?}

Previous studies in animals demonstrated that translational control is a widespread mechanism governing gametogenesis. The reliance on translational control to execute key transitions in meiosis and gamete development in females was attributed to the stockpiling of maternal RNAs in the future egg that made transcriptional control mechanisms ineffective. Our results show that translational control is a central mechanism for controlling late stages of gametogenesis also in budding yeast. This finding raises the interesting possibility that stockpiling of mRNAs and reliance on translational control are not strategies that arose during the evolution of large eggs but are ancient mechanisms associated with germ cell formation in general. Why eukaryotes have evolved to rely on translational regulatory mechanisms to control the meiotic divisions and late stages of gametogenesis is unclear. Perhaps general transcriptional downregulation associated with chromosome segregation interferes with high-level transcription of genes important for late stages of meiosis, such as cyclins, or the development of germ cell characteristics, such as spore wall components in yeast or sperm tail constituents in mammals. Making mRNAs prior to the meiotic divisions and then translating them as their gene products become required would be an elegant solution to this problem.

\section{Materials and methods}

\section{Strains and plasmids}

All strains are SK1 derivatives and are described in Supplemental Table S1. $p G A L-N D T 80, G A L 4 . E R$, and ime2-as1 constructs are described in Benjamin et al. (2003); CLB3-3HA is described in Carlile and Amon (2008); and the ZIP1-GFP construct is described in White et al. (2004). IME2st and 5' UTRA-CLB3-3HA were created by pop-in pop-out two-step mutagenesis as described in Storici et al. (2001). pGAL-5' UTR ${ }_{C L B 3} C L B 3-3 H A$, SPO20-3V5, GIP1-3V5, SPS1-3V5, SPO21-3V5, IME2-3V5, IME2st-3V5, and RIM4-3V5 were constructed using the PCRbased method described in Longtine et al. (1998). rim4-F139L3V5 and rim4-F349L-3V5 were constructed using PCR-based mutagenesis that involved transforming SK1 with the PCR product created by the following method: a forward primer containing the desired mutation, a reverse primer downstream from the RIM4 stop, and genomic DNA extracted from RIM43V5 (HIS3-marked) as a template.

\section{Sporulation conditions}

Strains were grown to saturation in YPD, diluted in BYTA $1 \%$ yeast extract, $2 \%$ tryptone, $1 \%$ potassium acetate, $50 \mathrm{mM}$ potassium pthalate) to $\mathrm{OD}_{600}=0.25$, and grown overnight. Cells were resuspended in sporulation medium $10.3 \%$ potassium acetate at $\mathrm{pH} 7,0.02 \%$ raffinose) to $\mathrm{OD}_{600}=1.8$ and sporulated with vigorous shaking at $30^{\circ} \mathrm{C}$. pGAL-NDT80 and GAL4.ER strains were released from the arrest by the addition of $1 \mu \mathrm{M}$ $\beta$-estradiol at $6 \mathrm{~h}$. pCUP1-IME1 pCUP1-IME4 strains were released from the arrest by addition of $25 \mu \mathrm{M} \mathrm{CuSO}{ }_{4}$ at $2 \mathrm{~h}$. In $n d t 80 \Delta$ strains, expression of $p G A L-5^{\prime} U T R_{C L B 3} C L B 3-3 H A$ was induced with $1 \mu \mathrm{M} \beta$-estradiol at $6 \mathrm{~h}$.

\section{Immunoblot analysis}

Samples were prepared as described in Moll et al. (1991), and immunoblots were prepared as described in Cohen-Fix et al. (1996). $\alpha$-HA was used at 1:1000 (Covance), $\alpha$-V5 was used at 1:2000 (Invitrogen), $\alpha$-Pgk1 was used at 1:5000 (Molecular Probes), and $\alpha$-thiophosphate ester was used at 1:1000 in TBST (Epitomics). $\alpha$-Mouse and $\alpha$-rabbit HRP-conjugated secondary antibodies (GE Healthcare) were used at 1:5000, except for Ime23V5 and Rim4-3V5, in which cases we used 1:10,000.

\section{Labeling and mass spectrometry identification of Ime2 substrates}

Whole-cell lysate kinase labeling and substrate identification were performed as described in Carlson and White (2012) with minor modifications. Four-hundred-microliter cultures of cells expressing ime2-as1-3V5 were induced to sporulation, harvested by centrifugation, washed once with Tris $(\mathrm{pH} 7.5)$, resuspended in breakage/kinase buffer (20 mM HEPES at pH 7.5, $137 \mathrm{mM}$ $\mathrm{NaCl}, 0.5 \mathrm{mM}$ EGTA, $25 \mathrm{mM} \mathrm{MgCl} 2,1 \% \mathrm{NP}-40,10 \%$ glycerol, $1 \times$ halt protease/phosphatase [Thermo Scientific]), and frozen in droplets in liquid nitrogen. Cells were lysed in liquid nitrogen using a Spex SamplePrep 6870 freezer mill. Lysates were thawed on ice and clarified by centrifugation $(25,000 \mathrm{rpm}$ for $1 \mathrm{~h})$, and protein amounts were determined by Bradford assay. Lysates were diluted to $4 \mathrm{mg}$ of protein/600 $\mu \mathrm{L}$ of kinase buffer. Lysates were immediately supplemented with $1 \mathrm{mM}$ guanosine 5-triphosphate (GTP), $50 \mu \mathrm{M}$ 6-Bn-ATP- $\gamma$-S, and $2 \mathrm{mM}$ TCEP and incubated for $60 \mathrm{~min}$ at $30^{\circ} \mathrm{C}$.

Following the kinase reaction, proteins were precipitated, and detergents were removed by methanol/chloroform precipitation. The protein pellet was disrupted with $50 \mu \mathrm{L}$ of urea and diluted $5 \times$ in ammonium acetate, $20 \mu \mathrm{g}$ of trypsin per milligram of protein was added, and samples were incubated overnight at room temperature with rotation.

Following trypsin digestion and desalting, lyophilized peptides were resuspended at $\sim 5 \mathrm{mg} / \mathrm{mL}$ in thiophosphate binding buffer ( $25 \mathrm{mM}$ Hepes at $\mathrm{pH} 7.0$ in $50 \%$ acetonitrile [ACN]) with $25 \mathrm{mg} / \mathrm{mL}$ albumin (BSA) and $5 \mathrm{mM}$ TCEP and titrated to a final $\mathrm{pH}$ of 5.5. The sample was combined with $100 \mu \mathrm{L}$ of SulfoLink bead slurry (Thermo/Pierce) and incubated overnight at room temperature in the dark with rotation. Beads were washed, suspended in $1 \mathrm{~mL}$ of binding buffer (25mM HEPES, 50\% MeCN at $\mathrm{pH} 7.0$ ), and loaded into a $45-\mathrm{cm} 530$ internal diameter fritted capillary using a helium bomb. The beads were washed with $0.1 \%$ acetic acid, and peptides were eluted with oxidizing buffer (Oxone, Sigma) into a POROS R2 column. This elution via oxidation resulted in the sulfur of the thiophosphate being substituted by an oxygen; thus, the eluted peptides were phosphorylated (rather than thiophosphorylated). Phosphopeptide enrichment was achieved by immobilized metal affinity chromatography (IMAC) (Carlson and White 2012). Peptides were eluted with $250 \mathrm{mM}$ sodium phosphate (pH 9.0).

Following offline IMAC processing and peptide elution onto a C18 precolumn, peptides were subsequently separated by 
reverse-phase high-performance liquid chromatography (HPLC) (Agilent) over a 150-min gradient before nanoelectrospray into a LTQ Orbitrap Elite mass spectrometer for data-dependent mode for phospho-peptide analysis (Thermo Fisher Scientific). Data files were converted to MASCOT generic format (.MGF) with DTASuperCharge (version 2.0b1) and searched with MASCOT (Matrix Science) against the SGD Saccharomyces cerevisiae strain S288C proteome with peptide tolerance of 10 parts per million (ppm) and tandem mass spectrometry (MS/MS) tolerance of $0.8 \mathrm{Da}$. Peptide sequences were initially filtered for phosphorylated sequences above a MASCOT ion score cutoff of 20 , which were detected in each of two process replicates. The spectra of this initial peptide substrate list were evaluated for accurate database identification with a computer-assisted manual validation software (Curran et al. 2013). MS/MS spectra of the phosphorylated peptides were manually inspected to confirm correct peptide identification and phosphorylation site localization.

\section{Other procedures}

Northern blot analysis was performed as described (Hochwagen et al. 2005) with minor modifications (see the Supplemental Material). Immunofluorescence was performed as described in Visintin et al. (1999). Acquisition of images was conducted using a DeltaVision microscope (Applied Biosystems). We used a 1:200 dilution of a mouse $\alpha-\mathrm{V} 5$ antibody to detect Rim4 and a 1:100 dilution of a rat $\alpha$-tubulin antibody to visualize spindles. Immunofluorescence samples were mounted in ProlongGold (Life Biosciences) that included DAPI. To visualize Zip1-GFP in combination with tubulin immunofluorescence, cells were fixed for $1 \mathrm{~h}$ in $3.7 \%$ formaldehyde prior to detection of tubulin by immunofluorescence. Quantification of Rim4 and tubulin staining as well as Zip1-GFP and DAPI staining was done with Worx software, which is built into the DeltaVision microscope.

Histone $\mathrm{Hl}$ kinase assays were performed as described in Hochwagen et al. (2005) with minor modifications (see the Supplemental Material). Quantification of blots and kinase assays was performed with NIH ImageQuant. Detailed descriptions of RNA pull-down of Rim4 and Rim4 RIP-chip are in the Supplemental Material.

\section{Acknowledgments}

We thank Frank Solomon, Terry Orr-Weaver, and Amon laboratory members for critical reading of the manuscript and helpful discussions. L.E.B. and G.A.B. are supported by American Cancer Society post-doctoral fellowships. A.S.G. is supported by a Ludwig Fund Post-doctoral Fellowship. C.X. and Y.X. are supported by an $\mathrm{NIH}$ grant to B.F. This research was supported by NIH grants GM62207 to A.A, AG10770 to J.S.W., and 5P01GM088297-04 to B.F. A.A. and J.S.W. are also investigators of the Howard Hughes Medical Institute.

\section{References}

Asaoka-Taguchi M, Yamada M, Nakamura A, Hanyu K, Kobayashi S. 1999. Maternal Pumilio acts together with Nanos in germline development in Drosophila embryos. Nat Cell Biol 1: 431-437.

Benjamin KR, Zhang C, Shokat KM, Herskowitz I. 2003. Control of landmark events in meiosis by the CDK Cdc28 and the meiosis-specific kinase Ime2. Genes Dev 17: 15241539.

Bishop AC, Ubersax JA, Petsch DT, Matheos DP, Gray NS, Blethrow J, Shimizu E, Tsien JZ, Schultz PG, Rose MD, et al.
2000. A chemical switch for inhibitor-sensitive alleles of any protein kinase. Nature 407: 395-401.

Brar GA, Yassour M, Friedman N, Regev A, Ingolia NT, Weissman JS. 2012. High-resolution view of the yeast meiotic program revealed by ribosome profiling. Science 335: 552-557.

Carlile TM, Amon A. 2008. Meiosis I is established through division-specific translational control of a cyclin. Cell 133: 280-291.

Carlson SM, White FM. 2012. Labeling and identification of direct kinase substrates. Sci Signal 5: pl3.

Carlson SM, Chouinard CR, Labadorf A, Lam CJ, Schmelzle K, Fraenkel E, White FM. 2011. Large-scale discovery of ERK2 substrates identifies ERK-mediated transcriptional regulation by ETV3. Sci Signal 4: rs11.

Chen HM, Futcher B, Leatherwood J. 2011. The fission yeast RNA binding protein Mmil regulates meiotic genes by controlling intron specific splicing and polyadenylation coupled RNA turnover. PLOS ONE 6: e26804.

Cohen-Fix O, Peters JM, Kirschner MW, Koshland D. 1996. Anaphase initiation in Saccharomyces cerevisiae is controlled by the APC-dependent degradation of the anaphase inhibitor Pds1p. Genes Dev 10: 3081-3093.

Curran TG, Bryson BD, Reigelhaupt M, Johnson H, White FM. 2013. Computer aided manual validation of mass spectrometrybased proteomic data. Methods 61: 219-226.

Dirick L, Goetsch L, Ammerer G, Byers B. 1998. Regulation of meiotic S phase by Ime2 and a Clb5,6-associated kinase in Saccharomyces cerevisiae. Science 281: 1854-1857.

Gavis ER, Lunsford L, Bergsten SE, Lehmann R. 1996. A conserved 90 nucleotide element mediates translational repression of nanos RNA. Development 122: 2791-2800.

Grandin N, Reed SI. 1993. Differential function and expression of Saccharomyces cerevisiae B-type cyclins in mitosis and meiosis. Mol Cell Biol 13:2113-2125.

Gray NK, Hentze MW. 1994. Iron regulatory protein prevents binding of the $43 \mathrm{~S}$ translation pre-initiation complex to ferritin and eALAS mRNAs. EMBO I 13: 3882-3891.

Groisman I, Huang YS, Mendez R, Cao Q, Theurkauf W, Richter JD. 2000. CPEB, maskin, and cyclin B1 mRNA at the mitotic apparatus: Implications for local translational control of cell division. Cell 103: 435-447.

Hepworth SR, Friesen H, Segall J. 1998. NDT80 and the meiotic recombination checkpoint regulate expression of middle sporulation-specific genes in Saccharomyces cerevisiae. Mol Cell Biol 18: 5750-5761.

Hochwagen A, Wrobel G, Cartron M, Demougin P, NiederhauserWiederkehr C, Boselli MG, Primig M, Amon A. 2005. Novel response to microtubule perturbation in meiosis. Mol Cell Biol 25: 4767-4781.

Holt LJ, Hutti JE, Cantley LC, Morgan DO. 2007. Evolution of Ime2 phosphorylation sites on Cdk1 substrates provides a mechanism to limit the effects of the phosphatase Cdc14 in meiosis. Mol Cell 25: 689-702.

Kato M, Han TW, Xie S, Shi K, Du X, Wu LC, Mirzaei H, Goldsmith EJ, Longgood J, Pei J, et al. 2012. Cell-free formation of RNA granules: Low complexity sequence domains form dynamic fibers within hydrogels. Cell 149: 753-767.

Kominami KI, Sakata Y, Sakai M, Yamashita I. 1993. Protein kinase activity associated with the IME2 gene product, a meiotic inducer in the yeast Saccharomyces cerevisiae. Biosci Biotechnol Biochem 57: 1731.

Kronja I, Orr-Weaver TL. 2011. Translational regulation of the cell cycle: When, where, how and why? Philos Trans $R$ Soc Lond 366: 3638-3652.

Longtine MS, McKenzie A, Demarini DJ, Shah NG, Wach A, Brachat A, Philippsen P, Pringle JR. 1998. Additional mod- 
ules for versatile and economical PCR-based gene deletion and modification in Saccharomyces cerevisiae. Yeast 14: 953-961.

Michlewski G, Caceres JF. 2010. RNase-assisted RNA chromatography. RNA 16: 1673-1678.

Miller MP, Unal E, Brar GA, Amon A. 2012. Meiosis I chromosome segregation is established through regulation of microtubule-kinetochore interactions. Elife 1: e00117.

Moll T, Tebb G, Surana U, Robitsch H, Nasmyth K. 1991. The role of phosphorylation and the CDC28 protein kinase in cell cycle-regulated nuclear import of the $S$. cerevisiae transcription factor SWI5. Cell 66: 743-758.

Murray LE, Rowley N, Dawes IW, Johnston GC, Singer RA. 1998. A yeast glutamine tRNA signals nitrogen status for regulation of dimorphic growth and sporulation. Proc Natl Acad Sci 95: 8619-8624.

Nakamura A, Seydoux G. 2008. Less is more: Specification of the germline by transcriptional repression. Development 135: 3817-3827.

Ostareck DH, Ostareck-Lederer A, Shatsky IN, Hentze MW. 2001. Lipoxygenase mRNA silencing in erythroid differentiation: The 3'UTR regulatory complex controls $60 \mathrm{~S}$ ribosomal subunit joining. Cell 104: 281-290.

Radford HE, Meijer HA, de Moor CH. 2008. Translational control by cytoplasmic polyadenylation in Xenopus oocytes. Biochim Biophys Acta 1779: 217-229.

Sari F, Heinrich M, Meyer W, Braus GH, Irniger S. 2008. The $\mathrm{C}$-terminal region of the meiosis-specific protein kinase Ime 2 mediates protein instability and is required for normal spore formation in budding yeast. J Mol Biol 378: 31-43.

Schisa JA. 2012. New insights into the regulation of RNP granule assembly in oocytes. Int Rev Cell Mol Biol 295: 233-289.

Schirmaier F, Philippsen P. 1984. Identification of two genes coding for the translation elongation factor EF-1 $\alpha$ of $S$. cerevisiae. EMBO J 3: 3311-3315.

Sia RA, Mitchell AP. 1995. Stimulation of later functions of the yeast meiotic protein kinase Ime2p by the IDS2 gene product. Mol Cell Biol 15: 5279-5287.

Smith HE, Mitchell AP. 1989. A transcriptional cascade governs entry into meiosis in Saccharomyces cerevisiae. Mol Cell Biol 9: 2142-2152.

Soushko M, Mitchell AP. 2000. An RNA-binding protein homologue that promotes sporulation-specific gene expression in Saccharomyces cerevisiae. Yeast 16: 631-639.

Storici F, Lewis LK, Resnick MA. 2001. In vivo site-directed mutagenesis using oligonucleotides. Nat Biotechnol 19: 773-776.

Sym M, Engebrecht JA, Roeder GS. 1993. ZIP1 is a synaptonemal complex protein required for meiotic chromosome synapsis. Cell 72: $365-378$.

Szwarcwort-Cohen M, Kasulin-Boneh Z, Sagee S, Kassir Y. 2009. Human Cdk2 is a functional homolog of budding yeast Ime2, the meiosis-specific Cdk-like kinase. Cell Cycle 8: 647-654.

Thompson B, Wickens M, Kimble J. 2007. Translational control in development. In Translational control in development and medicine (ed. MB Matthews, et al.), pp. 507-544. Cold Spring Harbor Laboratory Press, Cold Spring Harbor, NY.

Vardy L, Pesin JA, Orr-Weaver TL. 2009. Regulation of Cyclin A protein in meiosis and early embryogenesis. Proc Natl Acad Sci 106: $1838-1843$.

Visintin R, Hwang ES, Amon A. 1999. Cfil prevents premature exit from mitosis by anchoring Cdc14 phosphatase in the nucleolus. Nature 398: 818-823.

Weber SC, Brangwynne CP. 2012. Getting RNA and protein in phase. Cell 149: 1188-1191.

White EJ, Cowan C, Cande WZ, Kaback DB. 2004. In vivo analysis of synaptonemal complex formation during yeast meiosis. Genetics 167: 51-63. 


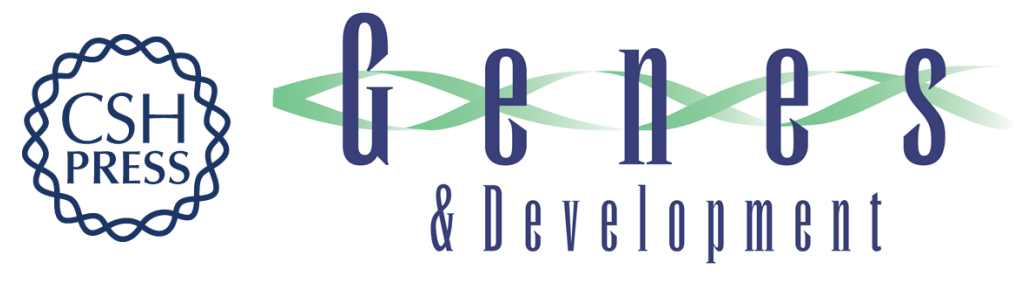

\section{A developmentally regulated translational control pathway establishes the meiotic chromosome segregation pattern}

Luke E. Berchowitz, Aaron S. Gajadhar, Folkert J. van Werven, et al.

Genes Dev. 2013, 27:

Access the most recent version at doi:10.1101/gad.224253.113

Supplemental http://genesdev.cshlp.org/content/suppl/2013/10/10/27.19.2147.DC1
Material

References This article cites 42 articles, 17 of which can be accessed free at: http://genesdev.cshlp.org/content/27/19/2147.full.html\#ref-list-1

Creative This article is distributed exclusively by Cold Spring Harbor Laboratory Press for the first Commons six months after the full-issue publication date (see

License http://genesdev.cshlp.org/site/misc/terms.xhtml). After six months, it is available under a Creative Commons License (Attribution-NonCommercial 3.0 Unported), as described at http://creativecommons.org/licenses/by-nc/3.0/.

Email Alerting Receive free email alerts when new articles cite this article - sign up in the box at the top Service right corner of the article or click here.

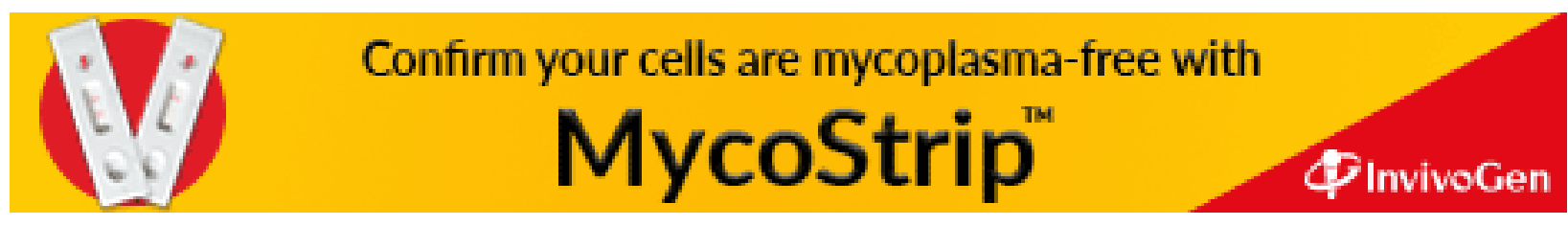

